\title{
MASTER
}

DR: 2943

\section{EVALUATION OF MATERIALS EXPOSED TO SCALE-CONTROL/NOZZLE-EXHAUST EXPERIMENTS AT THE SALTON SEA GEOTHERMAL FIELD}

3.A, Goldberg

R. P Rershaw

Febriary 8,1929

Work performed under the auspices of the U.S. Department of

Energy by the UCLLL under contract number W-7405-ENG 48 .

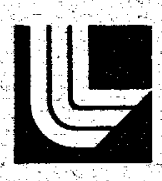

\section{IAWRENCE \\ LIVERMORE LABORATORY}

University of Caffornia/Livermore

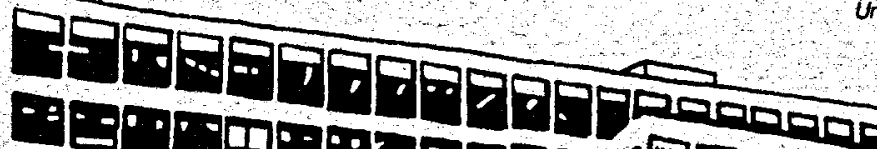

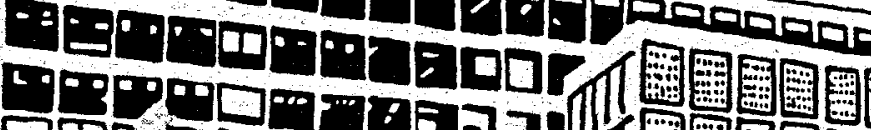

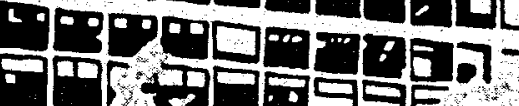

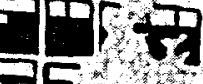

बि
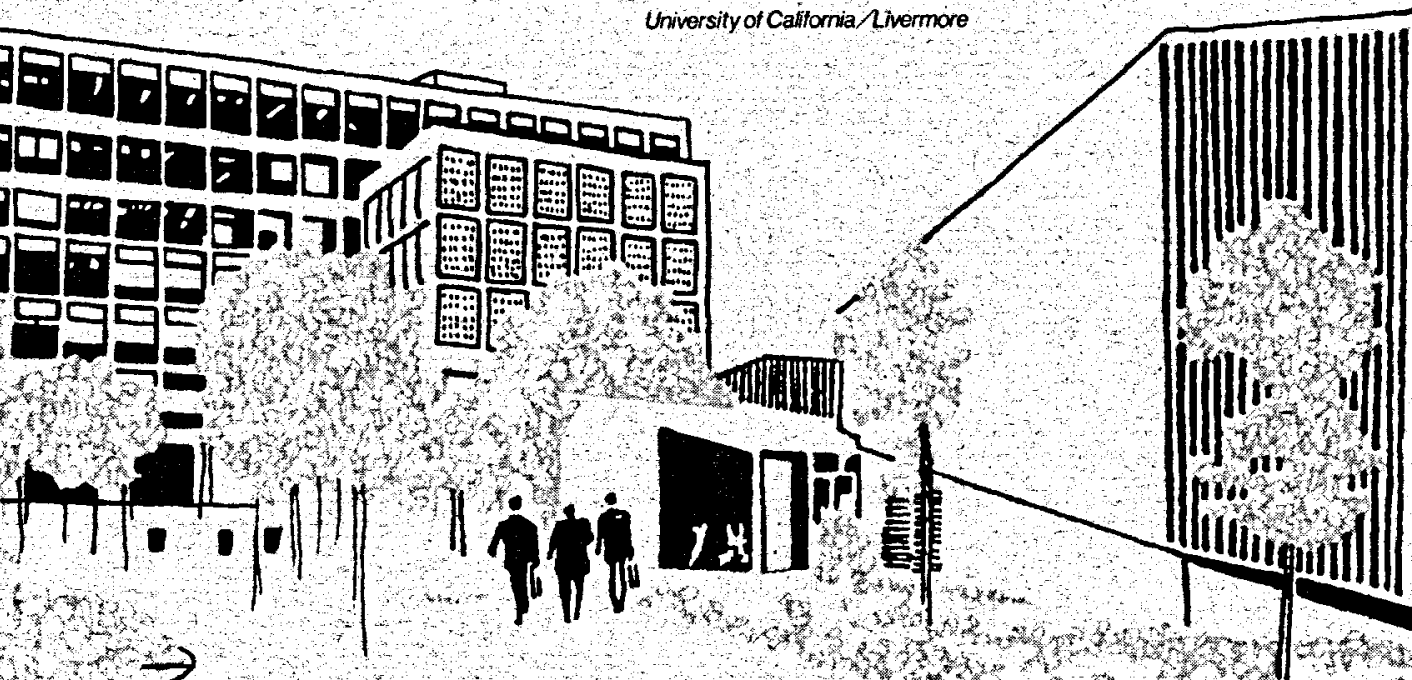

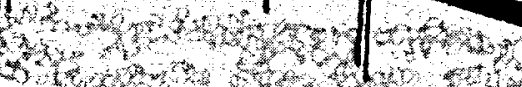

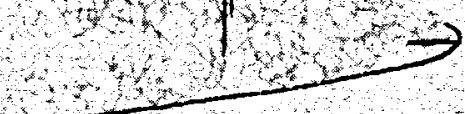




\section{DISCLAIMER}

This report was prepared as an account of work sponsored by an agency of the United States Government. Neither the United States Government nor any agency Thereof, nor any of their employees, makes any warranty, express or implied, or assumes any legal liability or responsibility for the accuracy, completeness, or usefulness of any information, apparatus, product, or process disclosed, or represents that its use would not infringe privately owned rights. Reference herein to any specific commercial product, process, or service by trade name, trademark, manufacturer, or otherwise does not necessarily constitute or imply its endorsement, recommendation, or favoring by the United States Government or any agency thereof. The views and opinions of authors expressed herein do not necessarily state or reflect those of the United States Government or any agency thereof. 


\section{DISCLAIMER}

Portions of this document may be illegible in electronic image products. Images are produced from the best available original document. 

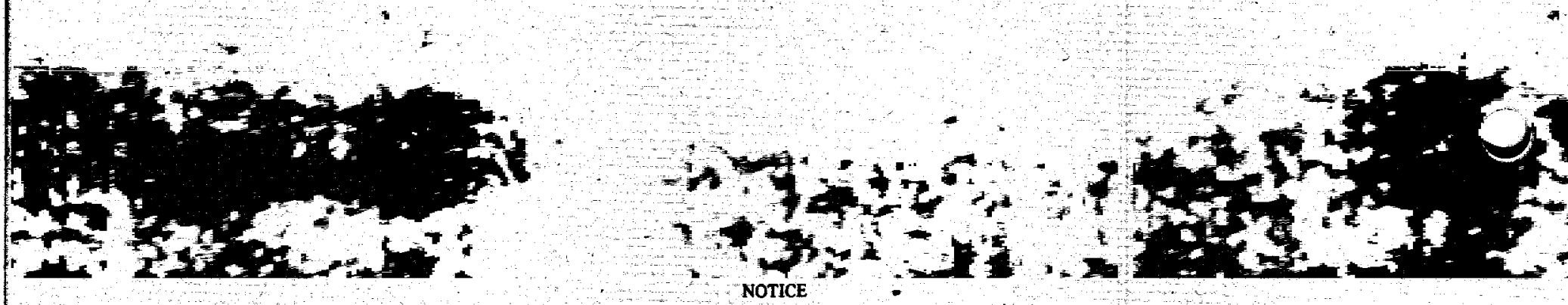

"This report was prepared as an account of work sponsored by the United States Government. Neither the United States nor the United States Department of Energy, nor eny of their employees, nor any of their contractors, subcontractors, or their employees, makes any warranty, express or implied, or assumes any legal liability or responsibility for the accuracy, completeness or usefulness of any information, apparatus, product or process disclosed, or represents that its use would not infringe privately-owned rights."
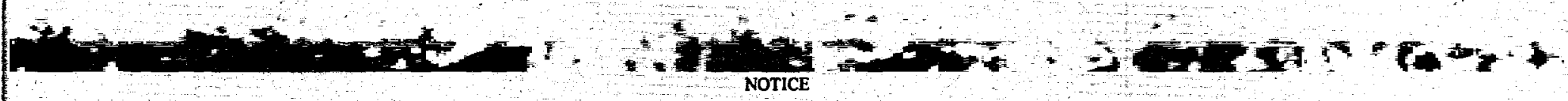

Reference to a company or product name does not imply approval or recommendation of the product by the University of California or the U.S. Department of Energy to the exclusion of others that may be suitable.

- $-4-5,-4$

Printed in the United States of America Available from

National Technical Information. Service

U.S. Department of Commerce

S285 Port Royal Road

Springfield, VA 22161

Price Printed Copy $\$$; Microfiche $\$ 3.00$

\begin{tabular}{|c|c|c|c|}
\hline & $\begin{array}{l}\text { Domestic } \\
\text { Price }\end{array}$ & Page Range & $\begin{array}{c}\text { Domestic } \\
\text { Price } \\
\end{array}$ \\
\hline $001-025$ & S 4.00 & $326-350$ & $\$ 12.00$ \\
\hline $026-050$ & 4.50 & $351-375$ & 12.50 \\
\hline $051-075$ & 5.25 & $376-400$ & 13.00 \\
\hline $076-100$ & 6.00 & $401 \quad 425$ & 13.25 \\
\hline $101-125$ & 6.50 & $426-450$ & 14.00 \\
\hline $126-150$ & 725 & $451-475$ & 14.50 \\
\hline $151-175$ & 8.00 & $476-500$ & 15.00 \\
\hline $176-200$ & 9.00 & $501-525$ & 15.25 \\
\hline $201-225$ & 9.25 & $526-550$ & 15.50 \\
\hline $226-250$ & 9.50 & $551-575$ & 16.25 \\
\hline $251-275$ & 10.75 & $576-600$ & 16.50 \\
\hline $276-300$ & $11: 00$ & $601-$ up & -1 \\
\hline $301-325$ & 11.75 & & \\
\hline
\end{tabular}

I/ Ad \$2.50 for tach additional 100 page increment from 601 pages up.
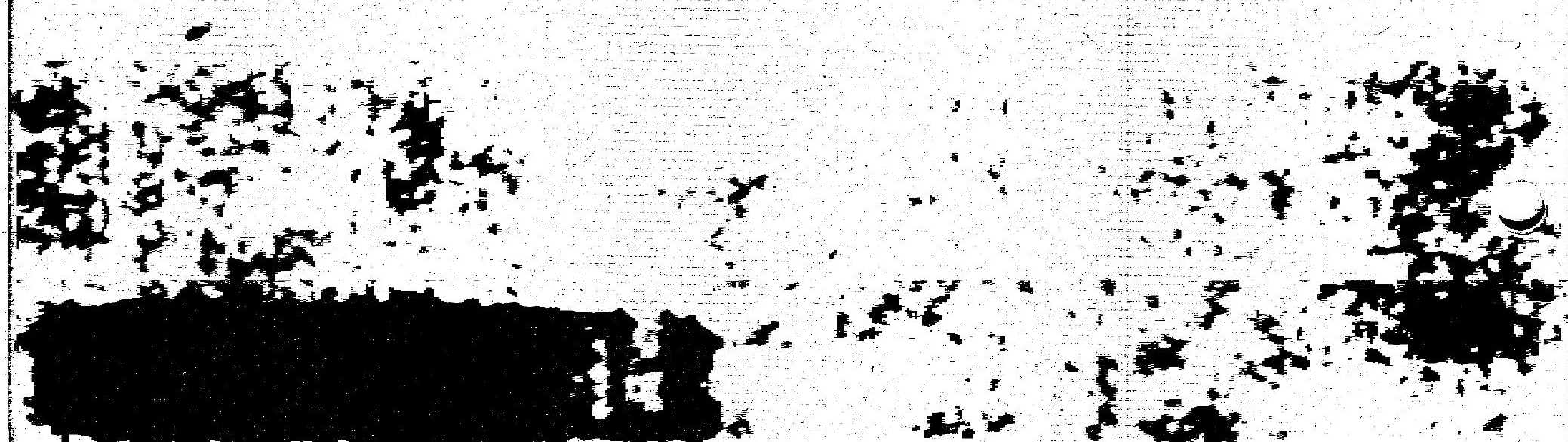


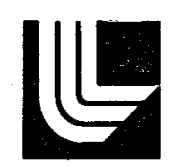

\title{
LAWRENCE LNERMORE LABORATORY
}

University of California/Livermore, California/94550

UCRL-52664

\section{EVALUATION OF MATERIALS EXPOSED TO SCALE-CONTROL/NOZZLE-EXHAUST EXPERIMENTS AT THE SALTON SEA GEOTHERMAL FIELD}

\author{
A. Goldberg \\ R. P. Kershaw
}

MS. date: February 8, 1979

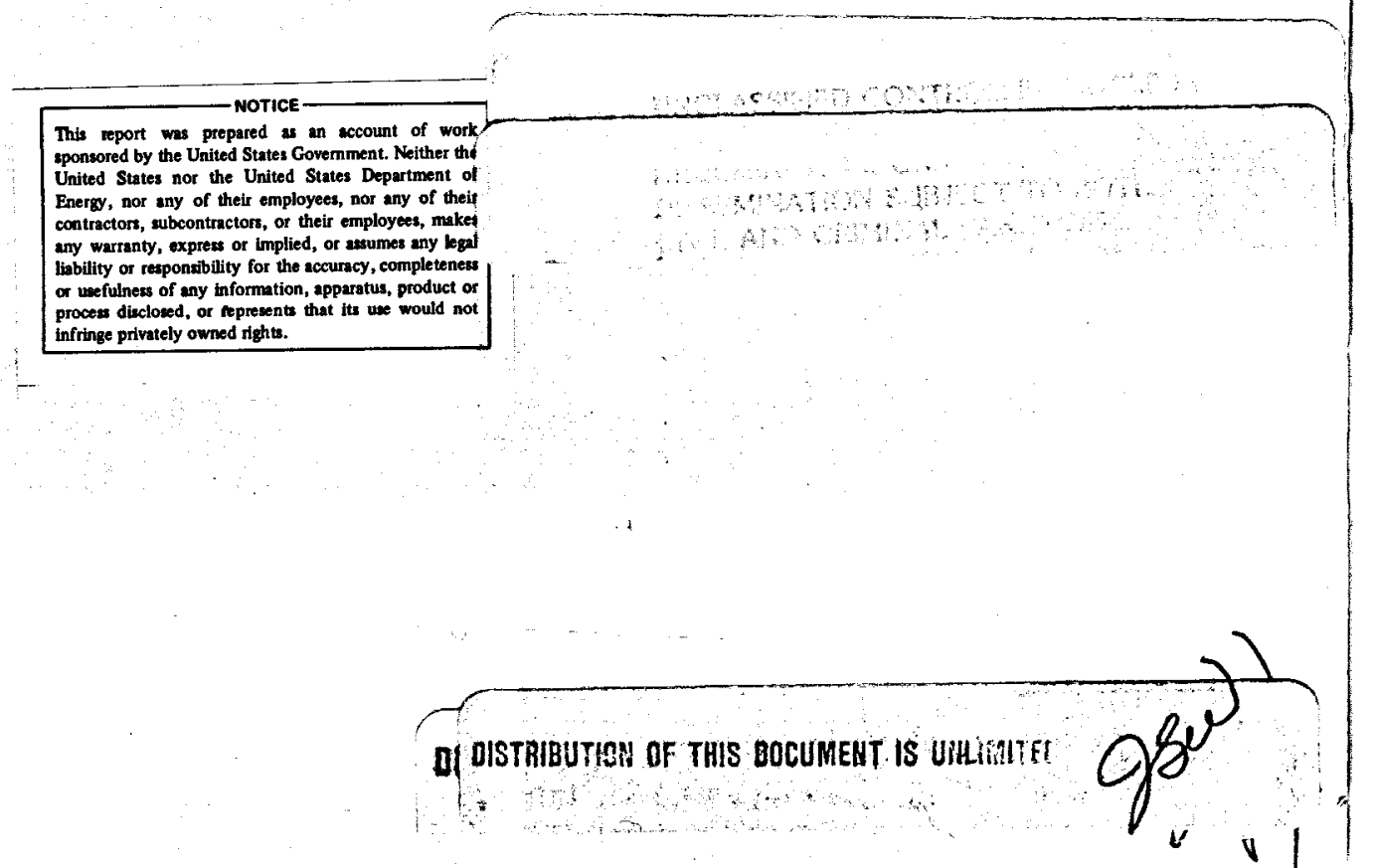




\section{CONTENTS}

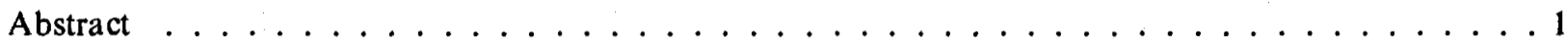



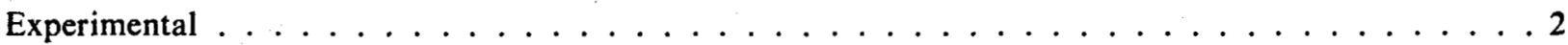

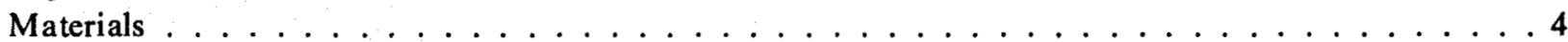

Evaluation of Exposed Materials $\ldots \ldots \ldots \ldots \ldots \ldots \ldots$

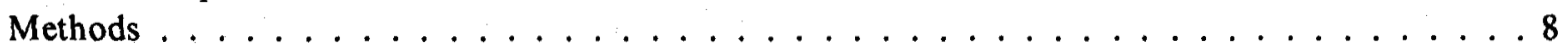

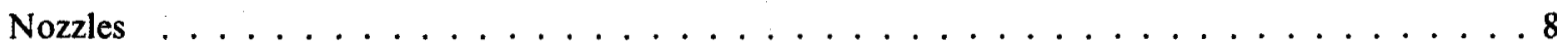

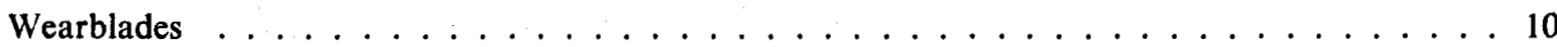

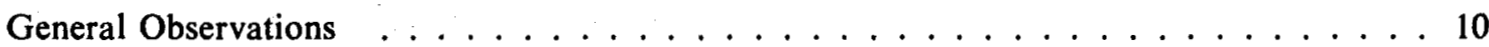

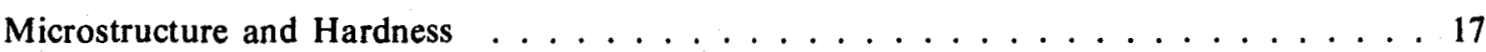

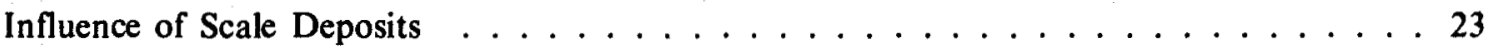

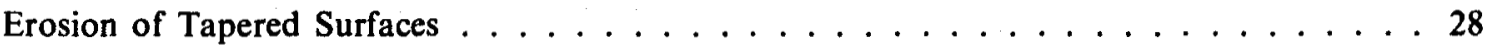

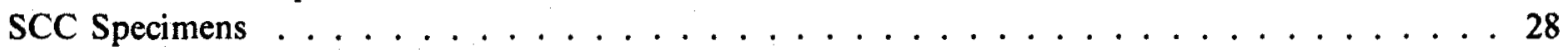

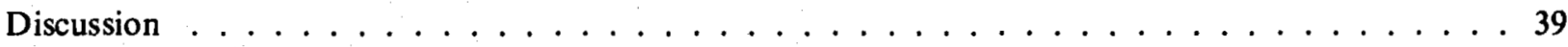

Summary .............................. 41

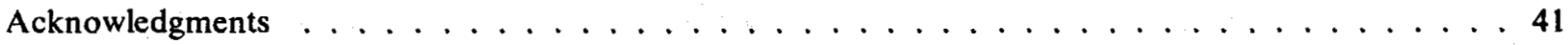

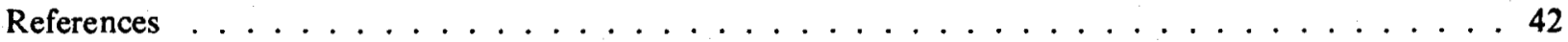




\title{
EVALUATION OF MATERIALS EXPOSED TO SCALE-CONTROL/NOZZLE-EXHAUST EXPERIMENTS AT THE SALTON SEA GEOTHERMAL FIELD
}

\begin{abstract}
We evaluated the erosion, corrosion, and stress corrosion cracking (SCC) of Ti-, $\mathrm{Co}-, \mathrm{Ni}-$, and $\mathrm{Fe}$-base alloy specimens that were used in scale-control tests performed at the Salton Sea geothermal field. Specimens were exposed to high-velocity, two-phase, $104^{\circ} \mathrm{C}$ nozzle exhaust that was produced by expanding acidified hypersaline, highly mineralized brine to atmospheric pressure through converging-diverging nozzles. We evaluated the exposed specimens using surface profilometer traces, light microscopy, scanning-electron microscopy, and energy dispersive spectroscopy analysis. We attributed the observed degradation largely to synergistic effects of erosion, corrosion, and stress. A principal mode of degradation appeared to be the formation and growth of corrosion-assisted erosion cavities; we propose that surface repassivation kinetics play a key role in the development of these cavities. We also suggest that scale deposits on the metal surface may either alter the mode of attack or act as protective barriers. We conclude that, of the potential turbineblade materials tested, the Ti-base alloys exhibited the best combination of resistance to erosion, corrosion, and SCC.
\end{abstract}

\section{INTRODUCTION}

The Lawrence Livermore Laboratory (LLL) Geothermal Energy Program,' has been conducting experiments at the LLL Field Test Station, located near Niland, California, to explore the potential use of Salton Sea geothermal field brines for electric power generation. The brines at this site are hypersaline, highly mineralized, and may exceed $300^{\circ} \mathrm{C}$.

In one of the energy-conversion systems considered for this application, the total flow of the wellhead is expanded through converging-diverging nozzles to drive an impulse turbine. Expansion of the brine from about $2 \mathrm{MPag}$ to atmospheric pressure causes cooling and mineral enrichment of the residual liquid and results in deposits of silica-rich scale that could seriously limit the operation of the turbine system. One possible method investigated for reducing and controlling this scale deposition was acidification of the brine with $\mathrm{HCl}$. Specimens of $\mathrm{Ti}-, \mathrm{Co}-, \mathrm{Ni}-$, and $\mathrm{Fe}$-base alloys, proposed as potential candidates for the totalflow turbine, were exposed to acidified brine to determine the effects of lowering the $\mathrm{pH}$ on scale deposition. In conjunction with these experiments, we evaluated the extent of erosion, corrosion, and stress-corrosioncracking (SCC) of samples exposed to these conditions.

This report describes our analysis of specimens from three series of field experiments. The test materials were exposed to acidified brine that had been expanded through converging-diverging nozzles to produce high-velocity, two-phase flow. A large portion of the results contained here was recently reported elsewhere ${ }^{2}$; we present additional analyses and the complete testing history of all exposed specimens here. Reference 1 describes the details of the entire LLL Geothermal Energy Program, including acidification for scale control and the analysis of scale deposition. 


\section{EXPERIMENTAL}

The quality of the brine at the wellhead was 10 to $20 \%$ vapor. To minimize variation of the system parameters, the liquid phase was separated from the vapor and used as the starting brine. Hydrochloric acid was then introduced through metering pumps $3 \mathrm{~m}$ upstream from the nozzles.

The composition of the brine varied significantly, not only as a result of changes in operating conditions, but also because of variations in the flow from the well.' Table 1 shows analyses of brines taken from the LLL separator on four different days. On other days, chlorine and total solids contents have ranged as widely as 10 to $15 \%$ and 17 to $25 \%$, respectively. The brine was relatively reducing, and the $\mathrm{pH}$ was generally about 5.8 .

Three parallel test stations were operated simultaneously but independently. In the first test series, acidified 0\%-quality brine (100\% liquid) was expanded; in the second and third test series, vapor was reintroduced into the acidified brine just upstream from each nozzle. The nozzle-inlet quality for the second test series was estimated at $5 \%$; for the third test series, we calculated qualities of $11 \%$ for two stations and $33 \%$ for the third station. The brine entered the nozzles under pressures between 1.5 and $2.5 \mathrm{MPag}$ at about $220^{\circ} \mathrm{C}$; velocities ranged from about $3 \mathrm{~m} / \mathrm{s}$ for $0 \%$-quality to about $80 \mathrm{~m} / \mathrm{s}$ for $33 \%$-quality inlet brine. The temperature of the brine expanded to atmospheric pressure was about $104^{\circ} \mathrm{C}$.

TABLE 1. Brine conditions and composition during tests. ${ }^{\mathbf{a}, \mathrm{b}}$

\begin{tabular}{|c|c|c|c|c|}
\hline & \multicolumn{4}{|c|}{ Date } \\
\hline & $6 / 29 / 76$ & $6 / 30 / 76$ & $8 / 8 / 76$ & $8 / 10 / 76$ \\
\hline Temperature, ${ }^{\circ} \mathrm{C}$ & 200 & 214 & 230 & 215 \\
\hline Pressure, MPa (gage) & 1.55 & 1.65 & 2.21 & 1.62 \\
\hline pH & & 5.7 & 5.8 & 6.1 \\
\hline \multicolumn{5}{|l|}{ Oxidation-reduction } \\
\hline potential, $\mathrm{mV}$ vs $\mathrm{H}_{2}$ & & & 192 & 177 \\
\hline Density, $\mathrm{g} / \mathrm{cm}^{3}$ & 1.12 & 1.12 & 1.13 & 1.14 \\
\hline \multicolumn{5}{|l|}{ Total solids, g/kg brine } \\
\hline (by evaporation) & 169 & 171 & 197 & 196 \\
\hline \multicolumn{5}{|c|}{ Elemental composition, ppm (wt) } \\
\hline Lithium & & & 128 & 135 \\
\hline Sodium & 40,900 & 42,100 & 41,200 & 42,700 \\
\hline Potassium & 6,900 & 7,000 & 6,600 & 6,500 \\
\hline Magnesium & 125 & 125 & 95 & 99 \\
\hline Calcium & 17,400 & 16,900 & 17,900 & 18,200 \\
\hline Strontium & & & 360 & 373 \\
\hline Barium & 54 & 85 & 115 & 118 \\
\hline Manganese & 502 & 494 & 565 & 570 \\
\hline Iron & 202 & 161 & 199 & 180 \\
\hline Copper & 1 & 1 & 1 & 1 \\
\hline Zinc & 188 & 183 & 275 & 285 \\
\hline Aluminum & & & & $\mathbf{I}$ \\
\hline Silicon & 181 & 187 & 190 & 200 \\
\hline Lead & 22 & 22 & 60 & 59 \\
\hline Tin & 23 & 23 & & \\
\hline Antimony & 4 & 4 & & \\
\hline Chlorine & 101,000 & 105,000 & 111,000 & 112,000 \\
\hline
\end{tabular}

aref. 1.

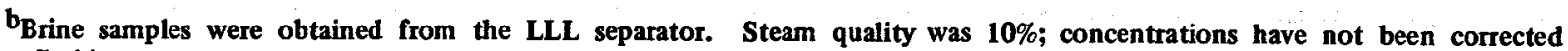
for flashing. 
Figure 1 shows a typical test assembly used to expand the brine and to evaluate both scale control and turbine materials. The test assembly was inserted into a $102-\mathrm{mm}$-diameter pipe elbow that received the expanded brine exhaust and also simulated the curved wall of a turbine chamber. The nozzle, with an expansion ratio of $8: 1$, was either monolithic or contained a removable insert. The wearblade, which represented the leading edge of a turbine blade, was $66 \mathrm{~mm}$ wide and $44 \mathrm{~mm}$ deep. We specified that the included angle of the wedge-shaped leading edge should be 0.35 rad with a tip radius of $254 \mu \mathrm{m}$. The tip was located $12.7 \mathrm{~mm}$ from the nozzle exit. The velocity of the two-phase nozzle exhaust at the tip was estimated to be $250 \mathrm{~m} / \mathrm{s}$ for $0 \%$ quality inlet brine and up to $380 \mathrm{~m} / \mathrm{s}$ for the two-phase inlet brine. ${ }^{3}$ Evaluation of nozzles and wearblades provided information on erosion and corrosion; results for scale deposition were presented elsewhere.

We also obtained information on stress corrosion cracking (SCC) from bent-beam, sheet specimens mounted in fixtures attached to the wearblade holder and loaded above their yield stress. These SCC specimens were mounted in pairs on each side of the wearblade so that the tensile-stressed surface of the front sample was exposed directly to the nozzle exhaust and the corresponding surface of the rear sample was shielded from such impact. The SCC specimens were $76 \mathrm{~mm}$ long, $6.4 \mathrm{~mm}$ wide, and between 0.65 and $2.5 \mathrm{~mm}$ thick; most were about $1.6 \mathrm{~mm}$ thick. With a few exceptions, specimens contained a machined SCC notch 125 $\mu \mathrm{m}$ deep. The SCC specimens also yielded information on erosion and erosion/corrosion.



FIG. 1. Test assembly for evaluation of scale and materials in nozzle-expansion field tests. In this photograph, Plexiglas was substituted for steel pipe to show the test specimens. 


\section{MATERIALS}

Preliminary tests with unacidified brine indicated that, of the alloys tested, Ti-base alloys were those most likely to withstand erosion/corrosion from the high-velocity nozzle-exhaust fluids. According to the literature, Ti-base alloys exhibit better resistance to SCC in chloride-bearing aqueous environments than the $\mathrm{Fe}-, \mathrm{Ni}$-, and $\mathrm{Co}$-base alloys. ${ }^{46}$ Our tests therefore emphasized the use of $\mathrm{Ti}$-base alloys, especially the Ti-6Al$4 \mathrm{~V}$ and Ti-6Al-4V extra-low-interstitial (ELI) alloys.

Nozzles fabricated from Ti-6Al-4V were used in all tests but two in which nozzles made of Haynes Stellite 6B and $\mathrm{Zr}$-grade CP-702 were used instead. In contrast, we tested many alloys as wearblades and SCC specimens, and Tables 2-4 list the test conditions to which each specimen was exposed; heat treatments of these materials are described in Tables 5 and 6. The first test series consisted of Runs 1-4, the second of Runs 5-10, and the third of Runs 11-12. The observations made on each exposed specimen, listed in the final columns of these tables, are discussed later in this report.

We experienced difficulty in correlating our observations with test conditions because these tests were designed primarily to study scale control. As a consequence, we could not generate a matrix of control variables that would provide a systematic materials analysis. Brine conditions frequently varied from test to

TABLE 2. Exposure conditions and evaluation summaries for wearblades.

\begin{tabular}{|c|c|c|c|c|c|c|c|c|c|}
\hline \multirow[b]{2}{*}{ Alloy } & \multirow[b]{2}{*}{$\begin{array}{c}\text { Heat- } \\
\text { treated } \\
\text { condition }\end{array}$} & \multirow[b]{2}{*}{$\begin{array}{c}\text { Hardness, } \\
\mathbf{R}_{\mathbf{C}}\end{array}$} & \multirow[b]{2}{*}{$\begin{array}{c}\text { Exposure, } \\
\mathbf{h} \\
\end{array}$} & \multirow[b]{2}{*}{$\begin{array}{l}\text { Run } \\
\text { No.b } \\
\end{array}$} & \multirow[b]{2}{*}{$\begin{array}{c}\text { Station } \\
\text { No. }\end{array}$} & \multirow[b]{2}{*}{$\begin{array}{c}\text { Inlet } \\
\text { brine } \\
\text { quality, } \\
\% \text { steam }\end{array}$} & \multirow[b]{2}{*}{$\begin{array}{c}\text { Exhaust } \\
\mathbf{p H}^{\mathbf{c}}\end{array}$} & \multicolumn{2}{|c|}{ Wear at blade tip } \\
\hline & & & & & & & & $\begin{array}{c}\text { Estimated } \\
\text { depth of } \\
\text { surface } \\
\text { recession, } \\
\mu \mathrm{m}\end{array}$ & $\begin{array}{l}\text { Maximum } \\
\text { depth of } \\
\text { cavities } \\
\text { below } \\
\text { recessed } \\
\text { surface, } \\
\mu \mathrm{m} \\
\end{array}$ \\
\hline Ti-6Ạl-4V & 2 & 34 & 110.5 & $1-4$ & 1 & $\mathbf{0}$ & 3.0 & $<\mathbf{2 0}$ & 30 \\
\hline Ti6Al-4V & 3 & 35 & 22.5 & 1 & 2 & 0 & 3.7 & 7 & 5 \\
\hline Ti-6Al-4V-case hardened & 19 & 36 & 22.5 & 1 & 3 & 0 & 5.9 & d & d \\
\hline $35 \mathrm{Co}-35 \mathrm{Ni}-20 \mathrm{Cr}-9.5 \mathrm{Mo} \mathrm{e}^{\mathrm{e}}$ & 29 & 47 & 37.0 & 2 & 2 & 0 & 3.1 & 35 & 45 \\
\hline Ni-16Cr-15.5Mo-5.5Fe-3.3W $t$ & 35 & 10 & 37.0 & 2 & 3 & $\mathbf{0}$ & 2.9 & 18 & 45 \\
\hline 2.2Cr-1Mo-Steel & 23 & 21 & 37.0 & 3 & 2 & $\mathbf{0}$ & 2.6 & $>240$ & 30 \\
\hline Ti-6Al-4V-carbonitrided & 19 & 36 & 37.0 & 3 & 3 & $\mathbf{0}$ & 3.6 & $<3$ & 10 \\
\hline $\mathrm{Co}-20 \mathrm{Cr}-14.5 \mathrm{~W}-9.5 \mathrm{Ni}-2.5 \mathrm{Feg}$ & 35 & 20 & 7.5 & 4 & 2 & 0 & 2.7 & $<2$ & 2 \\
\hline $\mathrm{Ti}-0.3 \mathrm{Mo}-0.8 \mathrm{Ni}$ & 21 & 6 & 25.0 & 4 & 3 & 0 & 3.9 & 30 & 40 \\
\hline Ti-6AI-4V-ELI & $\mathbf{5}$ & 34 & 20.1 & 5 & 1 & 5 & 56 & $<3$ & 3 \\
\hline TI-6Al-4V-ELI & 5 & 33 & 20.1 & $\mathbf{s}$ & 2 & 5 & $3 A$ & $<3$ & $\mathbf{s}$ \\
\hline TI-6Al-4V-ELI & 5 & 34 & 120.6 & $5-10$ & 3 & 5 & 3.4 & 70 & 60 \\
\hline $\mathrm{Co}-20 \mathrm{Cr}-14.5 \mathrm{~W}-9.5 \mathrm{Ni}-2.5 \mathrm{Feg}$ & 36 & 51 & 20.1 & 6 & 1 & 5 & 3.7 & $<7$ & $\mathbf{5}$ \\
\hline Ni-16Cr-15.5Mo-5.5Fe-3.3Wf & 34 & 43 & 20.1 & 6 & 2 & 5 & 3.4 & 14 & 55 \\
\hline $35 \mathrm{Co}-35 \mathrm{Ni}-20 \mathrm{Cr}-9.5 \mathrm{Mo}^{\mathrm{e}}$ & 28 & 46 & 20.0 & 7 & 1 & 5 & 3.6 & 22 & 25 \\
\hline Co-30Cr-4.5W-2.5Ni-2.5Fe-1Mo-1 $1 \mathrm{C}^{\mathrm{h}}$ & 37 & 37 & 18.5 & 7 & 2 & 5 & 3.7 & $<10$ & 7 \\
\hline TI6Al-4V-ELI & 7 & 30 & 20.8 & 8 & 1 & 5 & 3.2 & $<5$ & 10 \\
\hline TI-6Al-4V-ELI & 6 & 33 & 20.8 & 8 & 2 & $\mathbf{s}$ & 3.5 & $<3$ & 25 \\
\hline TI-6AJ-4V-ELI & 8 & 33 & 19.6 & 9 & 1 & $\mathbf{s}$ & 3.0 & $<5$ & 12 \\
\hline TI-6AJ-4V-ELI & 6 & 32 & 19.6 & 9 & 2 & $\mathbf{s}$ & 3.0 & 15 & 5 \\
\hline Ti-6Al-2Nb-1Ta-1Mo & 13 & 32 & 20.0 & 10 & 1 & 5 & 3.6 & 12 & 30 \\
\hline Ti-6Al-6V-2Sn & 14 & 43 & 20.0 & 10 & 2 & 5 & 3.8 & $<3$ & 3 \\
\hline Ti6Al-4V & 2 & 37 & 60.5 & $11-12$ & 1 & 11 & 2.4 & 20 & 5 \\
\hline Ti-6Al-4V-carbonitrided & 19 & 37 & 54.5 & $11-12$ & 2 & 33 & 2.3 & 18 & 8 \\
\hline Ti-6Al-4V-plasma sprayed & 20 & 45 & 11.0 & 11 & 3 & 11 & 2.3 & 220 & 40 \\
\hline $\mathrm{Ni}-16 \mathrm{Cr}-15.5 \mathrm{Ma}-5.5 \mathrm{Fe}-3.3 w^{f}$ & 34 & 47 & 49.5 & 12 & 3 & 11 & 2.3 & 200 & 20 \\
\hline
\end{tabular}

asee Tables 5 and 6.

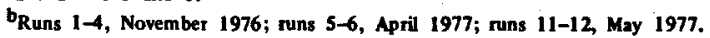

cooled nozzle-exhaust liquid; average value for run.

dContinued in run 3 at station 3.

eMP35N.

fHastelloy C-276.

Baynes 25.

hHaynes Stellite 6B. 
TABLE 3. Exposure conditions and evaluation summaries for Tibase SCC specimens.

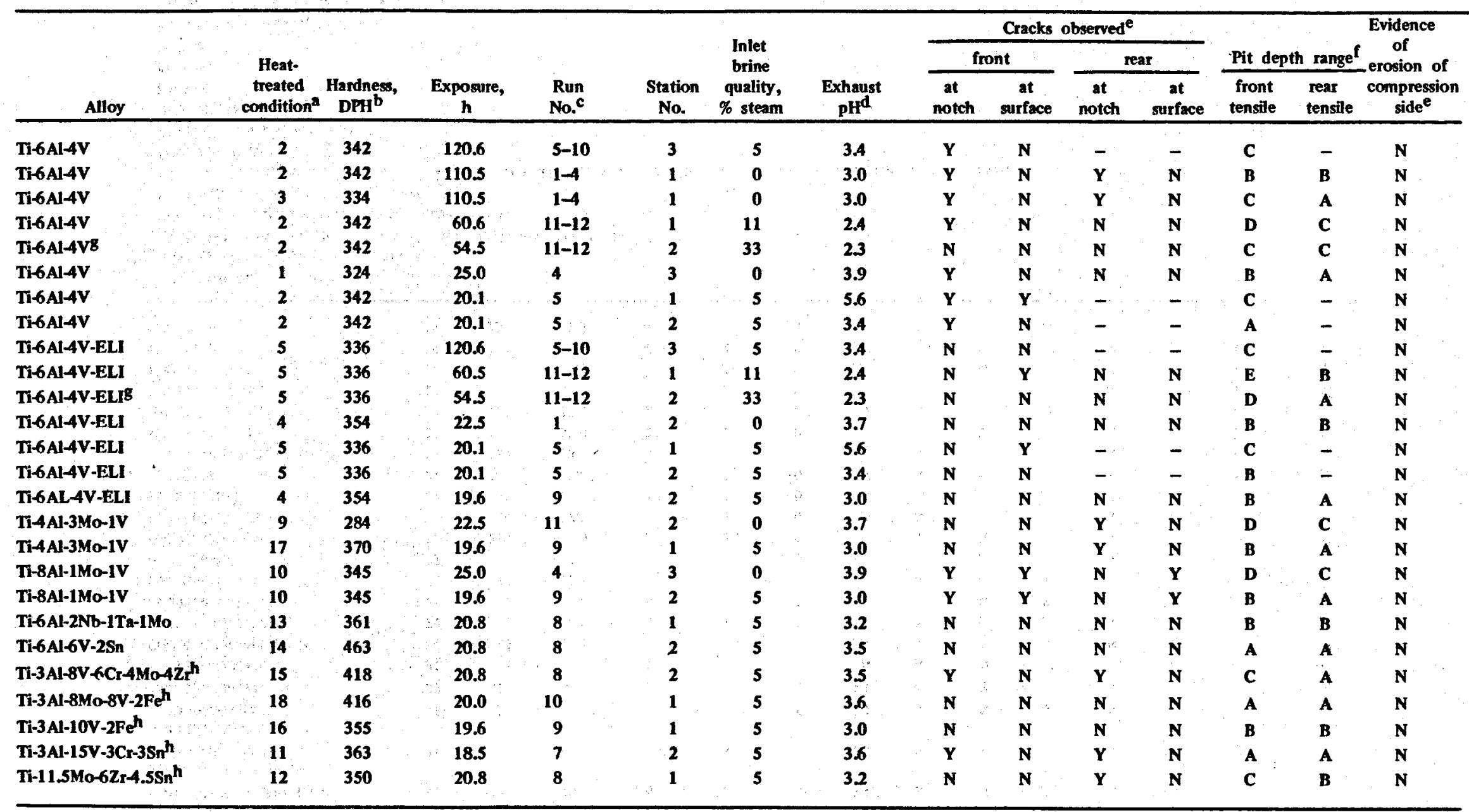

asee. Table 5.

b Average value for given heat treatment.

CRuns 1-4, November 1976; runs 5-10, April 1977; mus 11-12, May 1977.

Cooled nozzle-exhaust liquid; average value for nn

Y = yes; $N=$ no; dash = no specimen.

$\mathbf{f}_{A}=$ no degradation; $B=\leq 3 \mu \mathrm{m} ; C=4-10 \mu \mathrm{m} ; D=11-20 \mu \mathrm{m} ; E=21-50 \mu \mathrm{m} ; F=>50 \mu \mathrm{m}$, maximum pit depth range,

8Loaded to $30 \%$ yield strength, all other specimens loaded to within plastic range.

$h_{\beta}$ alloy. 
TABLE 4. Exposure conditions and evaluation summaries for Fe-, Ni-, and Co-base SCC specimens.

\begin{tabular}{|c|c|c|c|c|c|c|c|c|c|c|c|c|c|c|}
\hline \multirow[b]{3}{*}{ Alloy } & \multirow{3}{*}{$\begin{array}{c}\text { Heat- } \\
\text { treated } \\
\text { condition }^{2}\end{array}$} & \multirow[b]{3}{*}{$\begin{array}{l}\text { Hardness, } \\
\text { DPH }^{\mathbf{b}}\end{array}$} & \multirow[b]{3}{*}{$\begin{array}{c}\text { Exposure, } \\
\text { h }\end{array}$} & \multirow[b]{3}{*}{$\begin{array}{l}\text { Run } \\
\text { No. }\end{array}$} & \multirow[b]{3}{*}{$\begin{array}{l}\text { Station } \\
\text { No. }\end{array}$} & \multirow{3}{*}{$\begin{array}{c}\text { Inlet } \\
\text { brine } \\
\text { quality, } \\
\text { \% steam }\end{array}$} & \multirow[b]{3}{*}{$\begin{array}{c}\text { Exhaust } \\
\mathrm{pH}^{\mathrm{d}}\end{array}$} & \multicolumn{4}{|c|}{ Cracks observed $^{\mathbf{e}}$} & \multirow{2}{*}{\multicolumn{2}{|c|}{ Pit depth range $\mathrm{f}$}} & \multirow{3}{*}{$\begin{array}{c}\text { Evidence of } \\
\text { erosion of } \\
\text { compression } \\
\text { side }^{\mathrm{e}}\end{array}$} \\
\hline & & & & & & & & \multicolumn{2}{|c|}{ front } & \multicolumn{2}{|c|}{ rear } & & & \\
\hline & & & & & & & & $\begin{array}{c}\text { at } \\
\text { notch }\end{array}$ & $\begin{array}{c}\text { at } \\
\text { surface }\end{array}$ & $\begin{array}{c}\text { at } \\
\text { notch }\end{array}$ & $\begin{array}{c}\text { at } \\
\text { surface }\end{array}$ & $\begin{array}{c}\text { front } \\
\text { tensile }\end{array}$ & $\begin{array}{c}\text { rear } \\
\text { tensile }\end{array}$ & \\
\hline $\mathrm{Ni}-16 \mathrm{Cr}-15.5 \mathrm{Mo}-5.5 \mathrm{Fe}-3.3 \mathrm{Wg}$ & 33 & 407 & 60.5 & $11-12$ & 3 & 11 & 2.3 & $\mathbf{Y}$ & $\mathbf{N}$ & $\mathbf{Y}$ & $\mathbf{N}$ & c & c & $\mathbf{N}$ \\
\hline $\mathrm{Ni}-16 \mathrm{Cr}-15.5 \mathrm{Mo}-5.5 \mathrm{Fe}-3.3 \mathrm{Wg}$ & 33 & 407 & 20.1 & 6 & 2 & 5 & 3.4 & $\mathbf{N}$ & $\mathbf{N}$ & $\mathbf{Y}$ & $\mathbf{N}$ & c & $\mathbf{A}$. & $\mathbf{N}$ \\
\hline Ni-16Cr-15.5Mo-5.5Fe-3.3w8 & 32 & 224 & 20.1 & 6 & 2 & $\mathbf{s}$ & 3.4 & $\mathbf{s}^{\mathbf{h}}$ & $\mathbf{N}$ & $\mathbf{s}$ & $\mathbf{N}$ & $\mathbf{A}$ & $\mathbf{A}$ & $\mathbf{N}$ \\
\hline 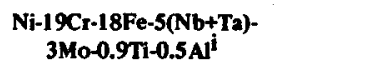 & 31 & 520 & 60.5 & $11-12$ & 3 & 11 & 2.3 & $\mathbf{s}$ & $\mathbf{Y}$ & $\mathbf{s}$ & $\mathbf{N}$ & $\mathbf{F}$ & A . & $\mathbf{N}$ \\
\hline $\begin{array}{c}\mathrm{Ni}-19 \mathrm{Cr}-18 \mathrm{Fe}-5(\mathrm{Nb}+\mathrm{Ta})- \\
3 \mathrm{MM}-0.9 \mathrm{Ti}-0.5 \mathrm{Al}^{\mathrm{i}}\end{array}$ & 31 & 520 & 18.5 & 7 & 2 & 5 & 3.7 & $\mathbf{Y}$ & $\mathbf{N}$ & $\mathbf{Y}$ & $\mathbf{N}$ & D & $\mathbf{A}$ & $\mathbf{N}$ \\
\hline $35 \mathrm{Co}-35 \mathrm{Ni}-20 \mathrm{Cr}-9.5 \mathrm{MoJ}$ & 27 & 514 & 37.0 & 2 & 2 & $\mathbf{0}$ & 3.1 & $\mathbf{N}$ & $\mathbf{Y}$ & $\mathbf{N}$ & $\mathbf{N}$ & $\mathbf{F}$ & $\mathbf{A}$ & $\mathbf{N}$ \\
\hline $35 \mathrm{Co}-35 \mathrm{Ni}-20 \mathrm{Cr}-9.5 \mathrm{Mo}^{\mathrm{j}}$ & 27 & 514 & 20.0 & 7 & 1 & 5 & 36 & $\mathbf{N}$ & $\mathbf{N}$ & $\mathbf{N}$ & $\mathbf{N}$ & c & $\mathbf{A}$ & $\mathbf{N}$ \\
\hline$C 0-20 C_{r}-14.5 W-9.5 W-2.5 \mathrm{Fe}^{k}$ & 30 & 285 & 20.1 & 6 & $\mathbf{1}$ & 5 & 3.7 & - & $\mathbf{N}$ & - & $\mathbf{N}$ & c & $\mathbf{A}$ & $\mathbf{N}$ \\
\hline $\mathrm{Fe}-20 \mathrm{Cr}-24 \mathrm{Ni}-6.5 \mathrm{Mo}$ & 22 & 190 & 20.0 & 10 & $\mathbf{1}$ & 5 & 3.6 & $\mathbf{N}$ & $\mathbf{N}$ & $\mathbf{N}$ & $\mathbf{N}$ & B & $\mathbf{A}$ & $\mathbf{N}$ \\
\hline $\mathrm{Fe}-29 \mathrm{Cr}-4 \mathrm{Mo}-2 \mathrm{Nj}$ & 22 & 251 & 20.0 & 10 & 2 & $\mathbf{s}$ & 3.8 & $\mathbf{s}$ & $\mathbf{N}$ & $\mathbf{s}$ & $\mathbf{N}$ & B & $\mathbf{A}$ & $\mathbf{N}$ \\
\hline Fe-29Cr4Mo & 22 & 238 & 22.5 & 1 & 3 & $\mathbf{0}$ & 5.9 & $\mathbf{m}$ & & & & & & \\
\hline $\mathrm{Fe}-29 \mathrm{Cr}-4 \mathrm{Mo}$ & 22 & 238 & $+37.0^{n}$ & 3 & 3 & 0 & 3.6 & $\mathbf{N}$ & $\mathbf{N}$ & $\mathbf{N}$ & $\mathbf{N}$ & c & B & $\mathbf{N}$ \\
\hline Fe-29Cr-4Mo & 22 & 238 & 20.0 & 10 & 2 & $\mathbf{5}$ & 3.8 & $\mathbf{Y}$ & $\mathbf{N}$ & $\mathbf{Y}$ & $\mathbf{N}$ & c & A & $\mathbf{N}$ \\
\hline Fe-26Cr-1Mo-0.3Ti & 22 & 188 & 37.0 & 2 & 3 & o & 2.9 & $\mathbf{N}$ & $\mathbf{N}$ & $\mathbf{N}$ & $\mathbf{N}$ & c & c & $\mathbf{Y}$ \\
\hline Fe-18Cr-2Mo & 22 & 203 & 22.5 & 1 & 3 & $\mathbf{0}$ & 5.9 & $\mathbf{m}$ & & & & & & \\
\hline Fe-18Cr-2Mo & 22 & 203 & $+37.0^{n}$ & 3 & 3 & 0 & 3.6 & $\mathbf{N}$ & $\mathbf{N}$ & $\mathbf{N}$ & $\mathbf{N}$ & c & B & $\mathbf{N}$ \\
\hline Fe-26Ni-14.5Cr-2Ti-1.2Mo-0.35A $\mathrm{A}^{\circ}$ & 26 & 429 & 20.1 & 6 & 1 & 5 & 3.7 & $\mathbf{s}$ & $\mathbf{N}$ & $\mathbf{s}$ & $\mathbf{N}$ & D & c & $\mathbf{N}$ \\
\hline 316 Stainless Steel & 22 & 185 & 37.0 & 2 & 2 & o & 3.1 & $\mathbf{N}$ & $\mathbf{Y}$ & $\mathbf{N}$ & $\mathbf{N}$ & $\mathbf{F}$ & $\mathbf{F}$ & $\mathbf{N}$ \\
\hline 304 Stainless Steel & 22 & 192 & 37.0 & 2 & 3 & $\mathbf{0}$ & 2.9 & $\mathbf{N}$ & $\mathbf{N}$ & $\mathbf{N}$ & $\mathbf{N}$ & c & c & $\mathbf{N}$ \\
\hline 410 Stainless Steel & 24 & 243 & 37.0 & 3 & 2 & o & 2.6 & $\mathbf{s}$ & $\mathbf{N}$ & $\mathbf{N}$ & $\mathbf{N}$ & $\mathbf{F}$ & $\mathbf{F}$ & $\mathbf{Y}$ \\
\hline 2.2Cr-1Mo Steel & 23 & 260 & $\mathbf{3 7 . 0}$ & 3 & 2 & o & 26 & $\mathbf{N}$ & $\mathbf{N}$ & $\mathbf{s}$ & $\mathbf{Y}$ & $\mathbf{F}$ & $\mathbf{F}$ & $\mathbf{Y}$ \\
\hline 4130 Steel + 0.5 Mo & 25 & 262 & 7.5 & 4 & 2 & $\mathbf{0}$ & 2.7 & $\mathbf{s}$ & $\mathbf{N}$ & $\mathbf{s}$ & $\mathbf{N}$ & $\mathbf{F}$ & D & $\mathbf{Y}$ \\
\hline 4130 Steel & 25 & 254 & 7.5 & 4 & 2 & o & 2.7 & $\mathbf{s}$ & $\mathbf{N}$ & - & - & $\mathbf{F}$ & - & $\mathbf{Y}$ \\
\hline
\end{tabular}

2See Table 6.



CRuns 1-4, November 1976; runs 5-10, April 1977; runs 11-12, May 1977

dCooled nozzle-exhaust liquid; average value for run.

'Y $=$ yes; $N=$ no; dash $=$ no specimen.

$T_{A}=$ no degradation; $B=\leq 3 \mu \mathrm{m} ; C=4-10 \mu \mathrm{m} ; D=11-20 \mu \mathrm{m} ; E=21-50 \mu \mathrm{m} ; \mathrm{F}=>50 \mu \mathrm{m}$, maximum pit depth range.

GHastelloy C-276.

hSmooth specimen, not notched.

inconel 718.

MP35N.

$\mathbf{k}_{\text {Haynes } 25 .}$

AL $6 \mathrm{X}$

m Continued in Run 3, Station 3.

${ }^{n}$ Total exposure of $59.5 \mathrm{~h}(22.5+37)$.

oA286. 
TABLE 5. Heat-treated conditions of Ti-base alloys.

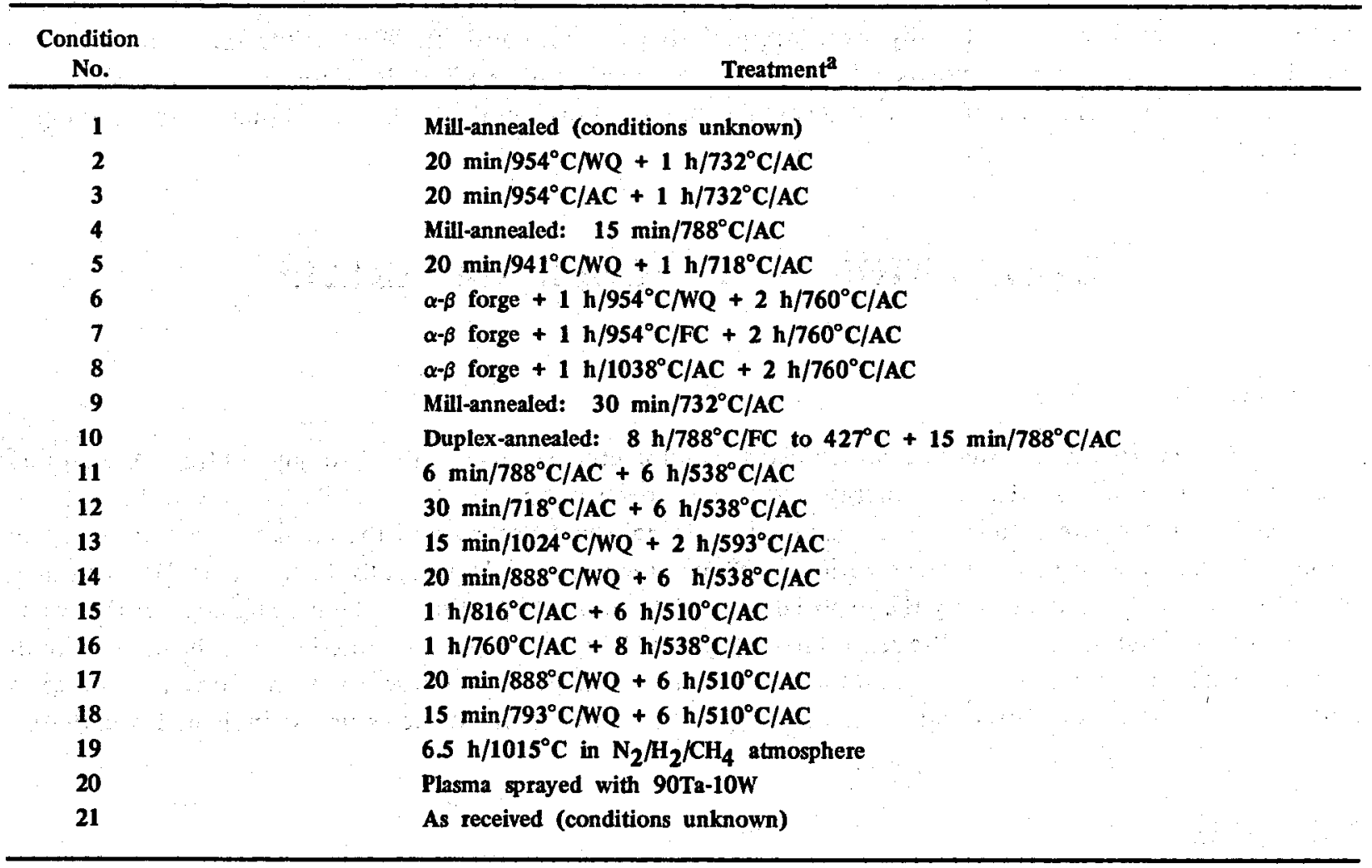

${ }^{\mathbf{a} W Q}=$ water quenched; $\mathbf{A C}=$ air cooled $\mathbf{F C}=$ furnace cooled.

TABLE 6. Heat-treated conditions of Fe-, Ni-, and Co-base alloys.

\begin{tabular}{|c|c|}
\hline $\begin{array}{c}\text { Condition } \\
\text { No. }\end{array}$ & Treatment ${ }^{\mathbf{a}}$ \\
\hline 22 & Mill-annealed (conditions unknown) \\
\hline 23 & $1 \mathrm{~h} / 954^{\circ} \mathrm{C} / W Q+2 \mathrm{~h} / 635^{\circ} \mathrm{C} / \mathrm{WQ}$ \\
\hline 24 & $1 \mathrm{~h} / 982^{\circ} \mathrm{C} / \mathrm{WQ}+2 \mathrm{~h} / 635^{\circ} \mathrm{C} / \mathrm{WQ}$ \\
\hline 25 & Quenched and tempered (conditions unknown) \\
\hline 26 & $50 \%$ cold rolled $+16 \mathrm{~h} / 704^{\circ} \mathrm{C} / \mathrm{AC}$ \\
\hline 27 & $1 \mathrm{~h} / 1066^{\circ} \mathrm{C} / \mathrm{AC}+40 \%$ cold rolled $+4 \mathrm{~h} / 538^{\circ} \mathrm{C} / \mathrm{AC}$ \\
\hline 28 & $1 \mathrm{~h} / 1066^{\circ} \mathrm{C} / \mathrm{AC}+50 \%$ cold rolled $+4 \mathrm{~h} / 538^{\circ} \mathrm{C} / \mathrm{AC}$ \\
\hline 29 & $1 \mathrm{~h} / 1066^{\circ} \mathrm{C} / \mathrm{AC}$ \\
\hline 30 & $6 \mathrm{~min} / 1024^{\circ} \mathrm{C} / \mathrm{WQ}$ \\
\hline 31 & $25 \%$ cold rolled $+8 \mathrm{~h} / 718^{\circ} \mathrm{C} / \mathrm{FC}$ to $621^{\circ} \mathrm{C}+18 \mathrm{~h} / 621^{\circ} \mathrm{C} / \mathrm{AC}$ \\
\hline 32 & $10 \mathrm{~min} / 1149^{\circ} \mathrm{C} / \mathrm{WQ}$ \\
\hline 33 & $10 \mathrm{~min} / 1149^{\circ} \mathrm{C} / \mathrm{WQ}+40 \%$ cold rolled $+100 \mathrm{~h} / 510^{\circ} \mathrm{C} / \mathrm{AC}$ \\
\hline 34 & $10 \mathrm{~min} / 1149^{\circ} \mathrm{C} / \mathrm{WQ}+60 \%$ cold rolled $+100 \mathrm{~h} / 500^{\circ} \mathrm{C} / \mathrm{AC}$ \\
\hline 35 & Mill-annealed (conditions unknown) \\
\hline 36 & $6 \mathrm{~min} / 120^{\circ} \mathrm{C} / \mathrm{WQ}+33 \%$ cold rolled $+100 \mathrm{~h} / 500^{\circ} \mathrm{C} / \mathrm{AC}$ \\
\hline 37 & Mill-annealed (conditions unknown) $+11 \%$ cold rolled \\
\hline
\end{tabular}

awQ $=$ water quenched; $A C=$ air cooled $; \mathrm{FC}=$ furnace cooled. 
test and between test stations. Even the untreated brine may have varied significantly with respect to such important corroding constituents as sulfur, arsenic, ammonia, carbon dioxide, etc.; the redox potential, quality, and $\mathrm{pH}$ also probably varied. Finally, exposure periods were not constant. Most of the specimens were exposed for $20 \mathrm{~h}$, several for as little as $7.5 \mathrm{~h}$, and one set for as long as $120 \mathrm{~h}$. Because of these variations, we emphasize the types of material degradation rather than the ranking of the alloys, although some ranking is apparent.

\section{EVALUATION OF EXPOSED MATERIALS}

\section{METHODS}

The wearblade tips were examined using profilometry (surface-analysis roughness traces), scanning electron microscopy (SEM), and energy dispersive spectroscopy (EDS); details are given below. All specimens, including wearblades, were examined using light microscopy and the etchants used are listed in Table 7. Nozzles and wearblades were sectioned through the center and parallel to the flow axis. We examined the entire nozzle sections but only the exposed tip and an adjacent portion of the leading edge of the wearblades. Approximately $25 \mathrm{~mm}$ of the central part of each SCC specimen was mounted so that the longitudinalthickness surface could be viewed. In all the photomicrographs presented here, the brine flowed from top to bottom for cross-section views and perpendicular to the photo for SEM views unless indicated otherwise.

\section{NOZZLES}

Figure 2 shows sections of the Stellite 6B nozzle (Rockwell hardness: $R_{C} 38$ ) exposed to $11 \%$-quality inlet brine for $60.5 \mathrm{~h}$. The nozzle was eroded mainly just downstream from the throat. Visual observations clearly showed erosion gouges running parallel to the flow direction; these can be seen at a low magnification in Fig. 2a. Figure 2c shows the erosion cavities at higher magnification; some damage is also seen at the nozzle inlet (Fig. 2a). Much less severe damage was observed in the throat region (Fig. 2b) and near the nozzle exit (Fig. 2d).

Figure 3 shows sections of a Ti-6Al-4V nozzle $\left(R_{C} 39\right)$ exposed for $60.5 \mathrm{~h}$ to the same nominal conditions as the Stellite 6B nozzle. Erosion was absent throughout the nozzle (Fig. 3a). An example of the erosionfree surface is shown in a magnified view of the nozzle throat (Fig. 3b). An interesting observation was an

TABLE 7. Etching conditions for light-microscopy specimens.

\begin{tabular}{|c|c|c|}
\hline Alloy & $\begin{array}{c}\text { Etchant; } \\
\text { (ml) }\end{array}$ & $\begin{array}{l}\text { Etching time, s; } \\
\text { (voltage, V) }\end{array}$ \\
\hline Ti-base alloys & Keller's reagent & \\
\hline Inconel 718 & $\mathrm{HCl}(10)+$ methanol$(90)$ & $1-2(50)$ \\
\hline Stellite 6B & $\mathrm{HCl}(97)+5 \% \mathrm{H}_{2} \mathrm{O}_{2}(3)$ & \\
\hline Haynes 25 & $\mathrm{HCl}(97)+5 \% \mathrm{H}_{2} \mathrm{O}_{2}(3)$ & \\
\hline Hastelloy C-276 & $5 \%$ chromic acid & $2-10(3)$ \\
\hline MP35N & $50 \%$ Fry's reagent $+50 \% \mathrm{HCl}^{\mathrm{a}}$ & \\
\hline 304 stainless steel & Kalling's reagent & \\
\hline 316 stainless steel & Kalling's reagent & \\
\hline 410 stainless steel & aqueous $10 \% \mathrm{FeCl}_{3}$ & \\
\hline Ferritic stainless steels & $\mathrm{HCl}(10)$ + methanol(90) & $3-5(6)$ \\
\hline Low-alloy steels & $2 \%$ nital & \\
\hline
\end{tabular}

aFresh solution, vigorously swabbed. 


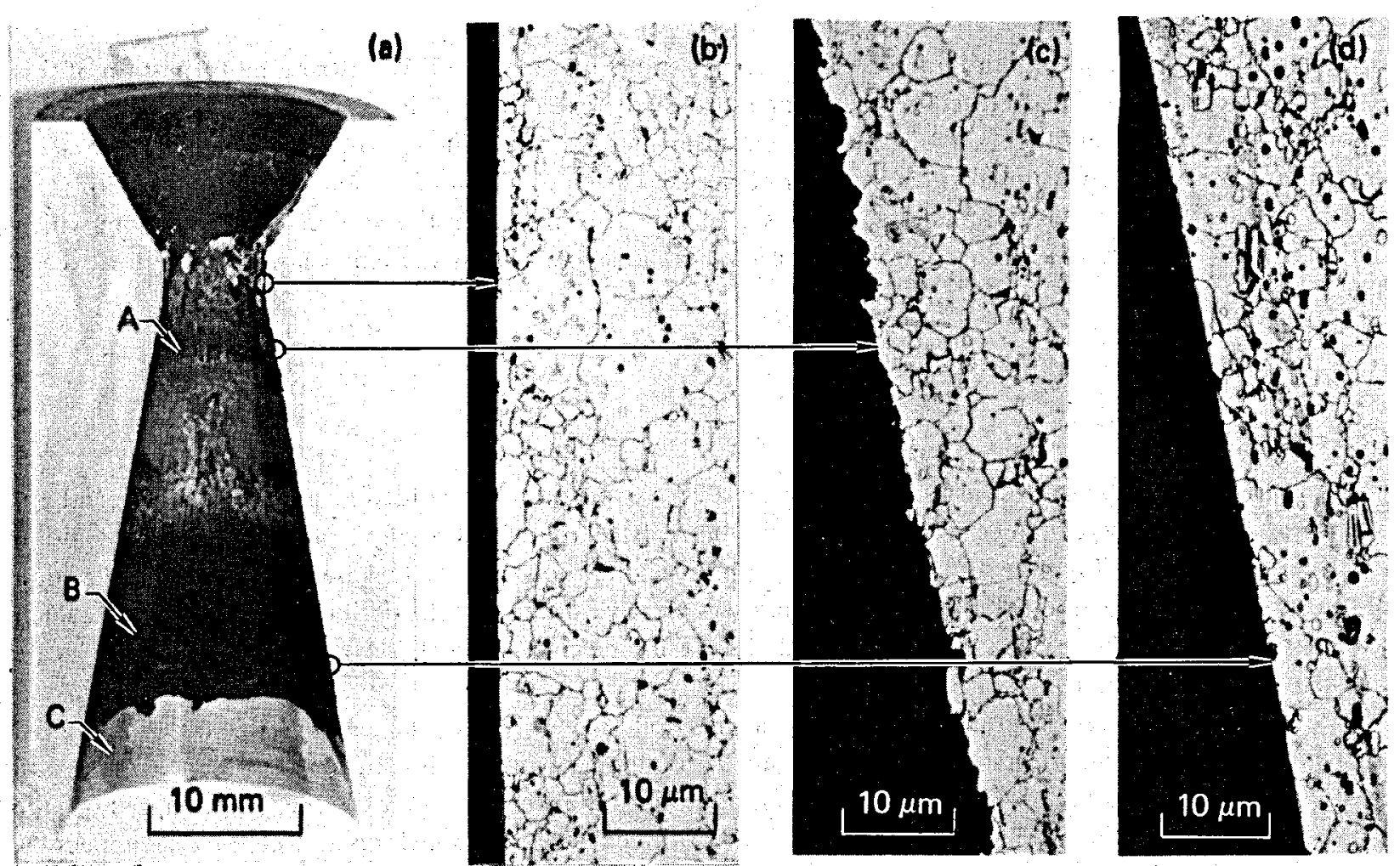

FIG. 2. Cross sections of Stellite 6B nozzle insert $\left(R_{C} 38\right)$ exposed for $60.5 \mathrm{~h}$ to $11 \%$-quality inlet brine, exhaust pH 2.4. (a) A, erosion gouges; B, scale deposit; $C$, scale flaked off. Views at increased magnification show (b) the throat region, which is virtually erosion-free, (c) an eroded surface downstream from the throat, and (d), the nozzle exit region, also virtually erosion-free.



FIG. 3. Cross sections of Ti-6Al-4V monolithic nozzle $\left(R_{C} 39\right)$ exposed for $60.5 \mathrm{~h}$ to $11 \%$-quality inlet brine, exhaust pH 2.3. (a) A, elliptical ridge of heavy scale deposit; B, scale-free surface; C, superficial scale deposits. (b) Example of erosionfree surface. (c) Scale deposit. 
elliptical ridge of scale several millimetres from the exit end (Figs. 3a and c). We attributed formation of this scale to a shock effect that resulted when the pressure of the expanding fluids dropped to the atmospheric chamber pressure at this location. ${ }^{3}$ Turbulence and an increase in residence time could cause such scale deposition. We observed a similar ridge in the $\mathrm{Zr}$ nozzle $\left(\mathrm{R}_{\mathrm{C}} 8\right)$ exposed simultaneously in another station; this nozzle also suffered no erosion. Such a ridge was probably also present in the Stellite 6B nozzle from which the scale had flaked off (Fig. 2a). The presence of a ridge suggests that the exit velocities did not exceed $380 \mathrm{~m} / \mathrm{s}^{3}$

\section{WEARBLADES}

\section{General Observations}

Figure 4a shows a test assembly following a 20-h exposure to expanded acidified brine. Typical appearances of exposed wearblades are shown in Fig. $4 \mathrm{~b}$ for a steel that was severely eroded and corroded and in Fig. $4 \mathrm{c}$ for a Ti-base alloy that suffered relatively minor degradation. Figure $4 \mathrm{c}$ shows that the central region of the wearblade exposed to the direct nozzle exhaust is clearly outlined by the peripheral scale deposits. Such scale deposits probably resulted from splashback from the pipe chamber walls. A relatively thin film of scale can also be seen in the central region.

We encountered several problems in measuring relative erosion of the leading-edge tips where most of the erosion took place. First, the degree of surface roughness and the location and presence of erosion cavities were found to vary with successive metallographic repolishings. For example, Figs. 5a-c show the cross section of an exposed Ti-6Al-4V wearblade after three successive polishing and etching sequences. A relatively deep cavity is seen only in Fig. $5 \mathrm{~b}$. Second, examination of sections of several unexposed wearblades indicated that the tips had not always been machined accurately to the specified $254-\mu \mathrm{m}$ radius, and this resulted in either a partially flattened or unsymmetrical tip. Although this did not affect scale-control, we were unable to determine wearblade erosion by simply examining surface recession alone. Our evaluations were consequently based on a combination of observations using profilometer traces and SEM of the exposed surface and light microscopy of cross sections.

Surface traces were taken along the tip of the leading edge of wearblades using a Gould Surfanalyzer 1200 with a $50-\mathrm{mg}$ diamond tip stylus $(2.5-\mu \mathrm{m}$ tip radius). Scale, if present, was then removed from the leading-edge tip using a plastic scraper, and the wearblades were cleaned ultrasonically in a soap solution. Comparisons of traces obtained from specimens before exposure, after exposure, and after removal of scale along the tip surface showed that erosion occurred only in the central region that was exposed to the direct exhaust; this was confirmed by microscopic examination. We could thus measure the extent of erosion by comparing the center and the extremities of the trace.

Figure 6 shows portions of traces taken along the tip of Ti-6Al-4V $\left(R_{C} 36\right)$ and Hastelloy $\mathrm{C}-276$ $\left(R_{C} 46\right)$ wearblades exposed for 60.5 and $49.5 \mathrm{~h}$, respectively, to $11 \%$-quality inlet brine with exhaust pH 2.3. (The $\mathrm{pH}$ values are the average of measurements of cooled samples taken from the liquid fraction of the nozzle exhaust.) Figures 7 and 8 show cross sections of these two wearblades and confirm the trace results. The Ti$6 \mathrm{Al}-4 \mathrm{~V}$ alloy eroded very little with the tip surface receding about $20 \mu \mathrm{m}$; the C-276 alloy eroded by an order of magnitude greater, about $200 \mu \mathrm{m}$. In both cases, erosion was considerably less along the tapered surfaces than at the tips. The erosion in the C-276 alloy (Fig. 8) progressed deeper in the light etching bands than in the dark etching bands. (The differential etching is probably due to chemical segregation.)

Although a large number of coated wearblades and ceramic wearblades were available, only three such wearblades were exposed because of time limitations and the demands and priorities of the scale-control program. Figure 9 shows sections of two Ti-6Al-4V wearblades with treated surfaces that we evaluated in the third test series. The wearblade surface shown in Fig. 9a was coated with $90 \mathrm{Ta}-10 \mathrm{~W}\left(\mathrm{R}_{C} 45\right)$ by plasma spraying; it was exposed to $11 \%$-quality inlet brine for only $11.5 \mathrm{~h}$. The wearblade shown in Fig. $9 \mathrm{~b}$ was carbonitrided in a $\mathrm{N}_{2} / \mathrm{H}_{2} / \mathrm{CH}_{4}$ atmosphere to give a surface hardness of $\mathrm{R}_{\mathrm{C}} 37$. It was exposed in four successive runs to $33 \%$-quality inlet brine for $54.5 \mathrm{~h}$. The low hardness measurement we obtained apparently resulted from penetration of the diamond indentor through the carbonitrided surface and into the base metal. The $\mathrm{pH}$ of the four runs averaged close to 2.3 . 
(a)

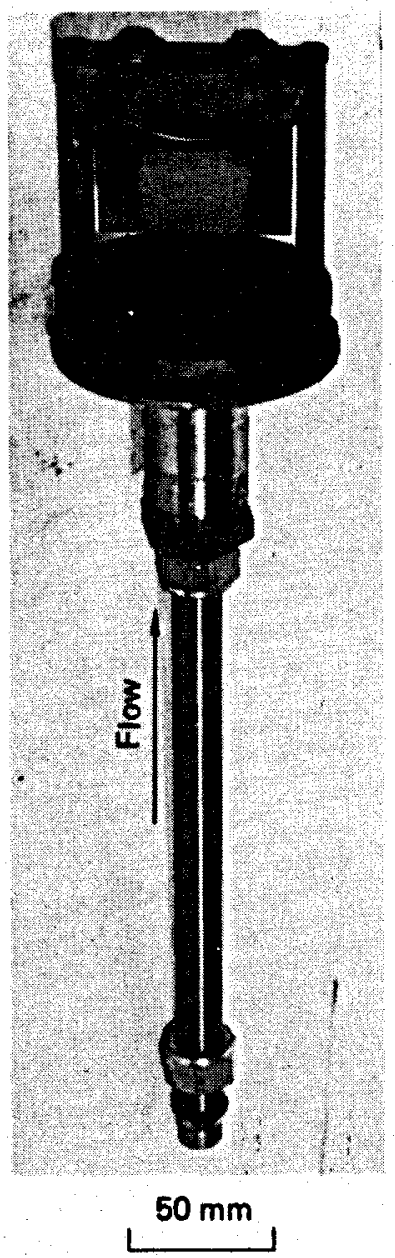

(b)

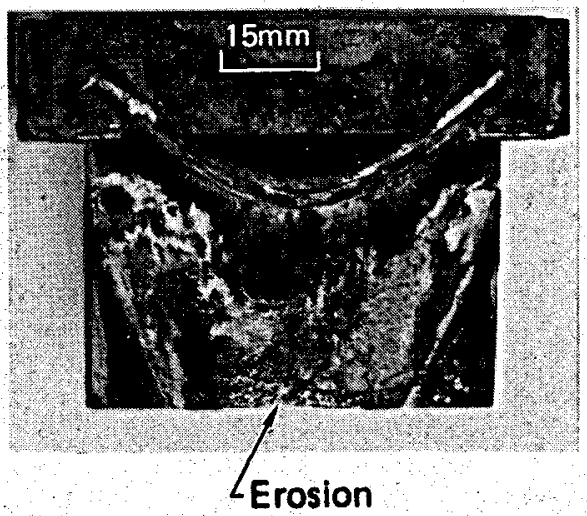

(c)

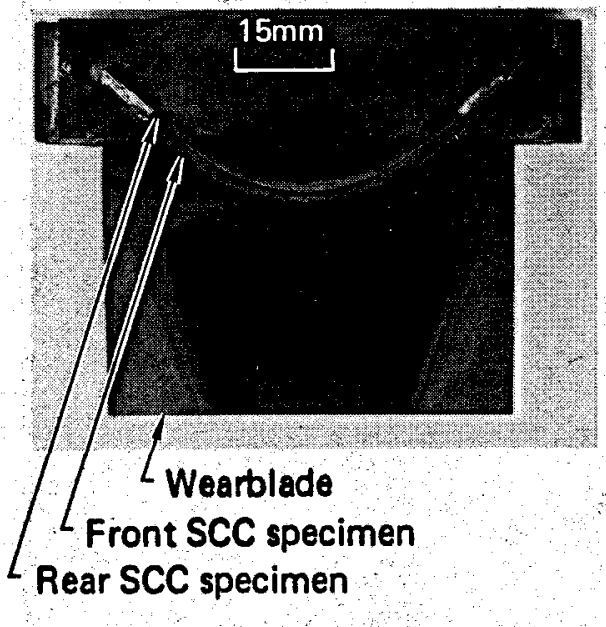

FIG. 4. (a) Test assembly with mounted wearblade and SCC specimens. (b) Wearblade made of $2.2 \mathrm{Cr}-1 \mathrm{Mo}$ steel showing combined effects of erosion and corrosion. (c) Wearblade made of erosion/corrosion-resistant Ti-6Al-4V alloy showing a nozzle-exhaust flow pattern.

The tip of the 90Ta- $10 \mathrm{~W}$-coated wearblade eroded $220 \mu \mathrm{m}$ with pits up to $40 \mu \mathrm{m}$ deep below the receded surface; the carbonitrided wearblade tip eroded only $18 \mu \mathrm{m}$. The severe erosion of the former surface was probably due to the poor bonding between the deposited particles, as suggested by the presence of numerous voids.

The hardened surface case of the wearblade in Fig. $9 \mathrm{~b}$ consisted of several distinct layers. The outer layer, about $1 \mu \mathrm{m}$ deep, was too thin for valid hardness measurements, but a liberal interpretation of microprobe analysis suggested that it consisted of TiN $(D P H \sim 1200)$. This layer appeared highly erosion/corrosion resistant, but once penetrated, erosion progressed at a rate characteristic of the base alloy. $\mathrm{H}$ ardness traverses across the Ti-6Al-4V carbonitrided sections gave values ranging from DPH 750 near the surface that gradually decreased to DPH $\sim 380$ in the base metal about $500 \mu \mathrm{m}$ below the surface.

Erosion cavities were present in all exposed wearblades. Figure 10 shows light microscopy and SEM views of the leading-edge tips for two Ti-6Al-4V-ELI wearblades $\left(R_{C} 32\right.$ and $\left.R_{C} 34\right)$ exposed to 5\%-quality inlet brine (exhaust pH 3.4) for $20.1 \mathrm{~h}$ and $120.6 \mathrm{~h}$, respectively. Both series of SEM photomicrographs show the presence of distinct microscopic cavities along the entire eroded tip-surfaces. Comparing the cross sections and SEM views for the 20.1 - and 120.6-h exposures (Figs. 10a,c,e,g, and b,d,f,h, respectively) suggests that 

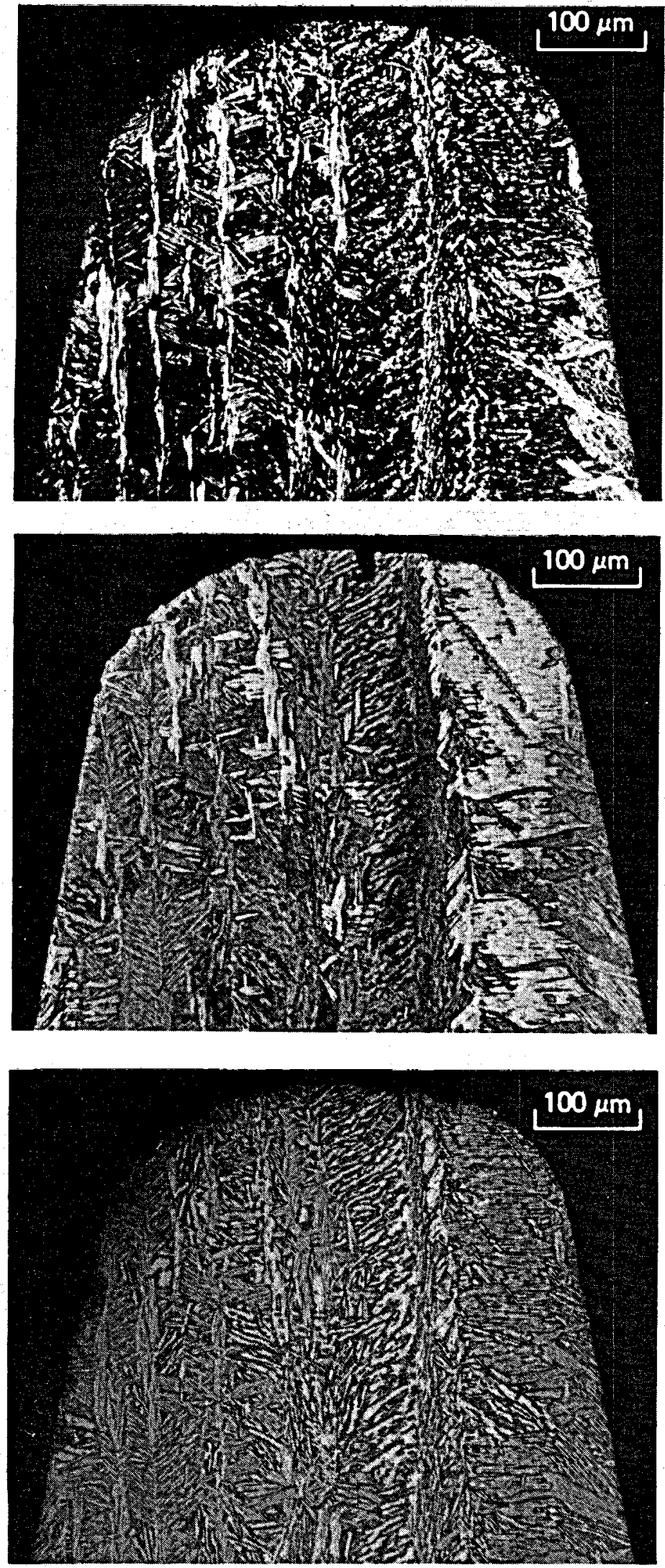

FIG. 5. Cross sections of a Ti-6Al-4V wearblade $\left(R_{C} 34\right)$ exposed for $110.5 \mathrm{~h}$ to $0 \%$ quality inlet brine, exhaust pH 3.0. Views (a-c) show the surface structure observed following each of three successive polish-etch sequences on the same surface section. 


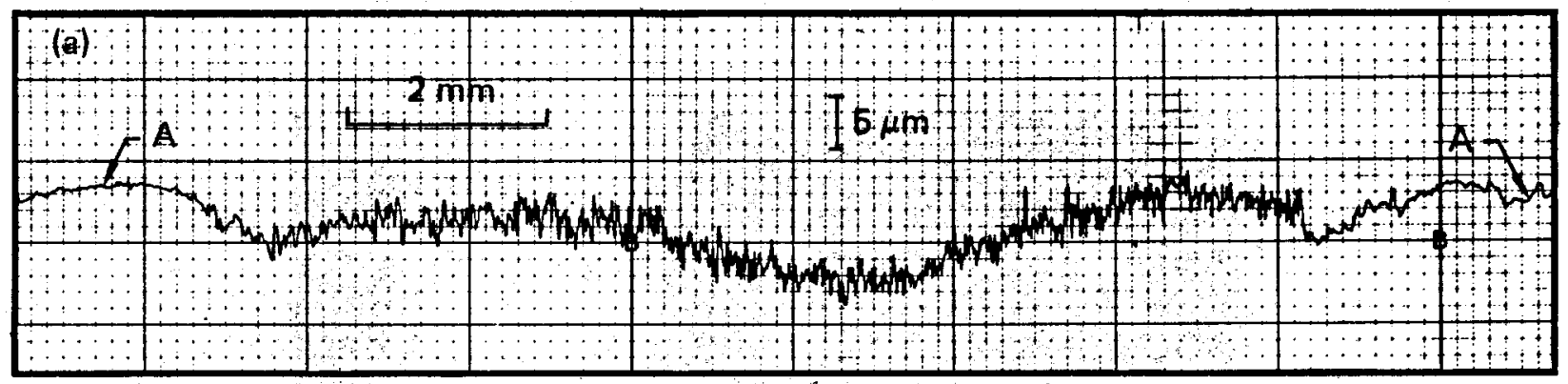

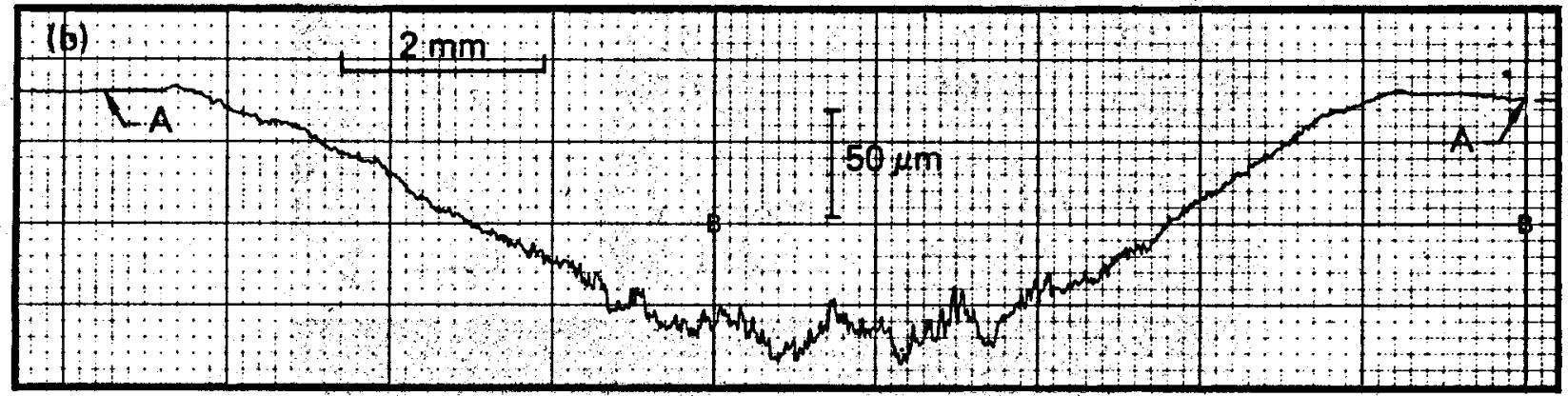

FIG. 6. Surface traces along the tip of the leading edge of (a) Ti-6Al-4V ( $R_{C} 36$ ) and (b) Hastelloy C-276 $\left(R_{C} 46\right)$ wearblades exposed to $11 \%$-quality inlet brine for 60.5 and $49.5 \mathrm{~h}$ at exhaust $\mathrm{pH} 2.4$ and 2.3 , respectively; $A$ indicates the region outside of direct nozzle exhaust where no erosion occurred. The vertical scale of trace (b) is five times greater than that of trace (a).
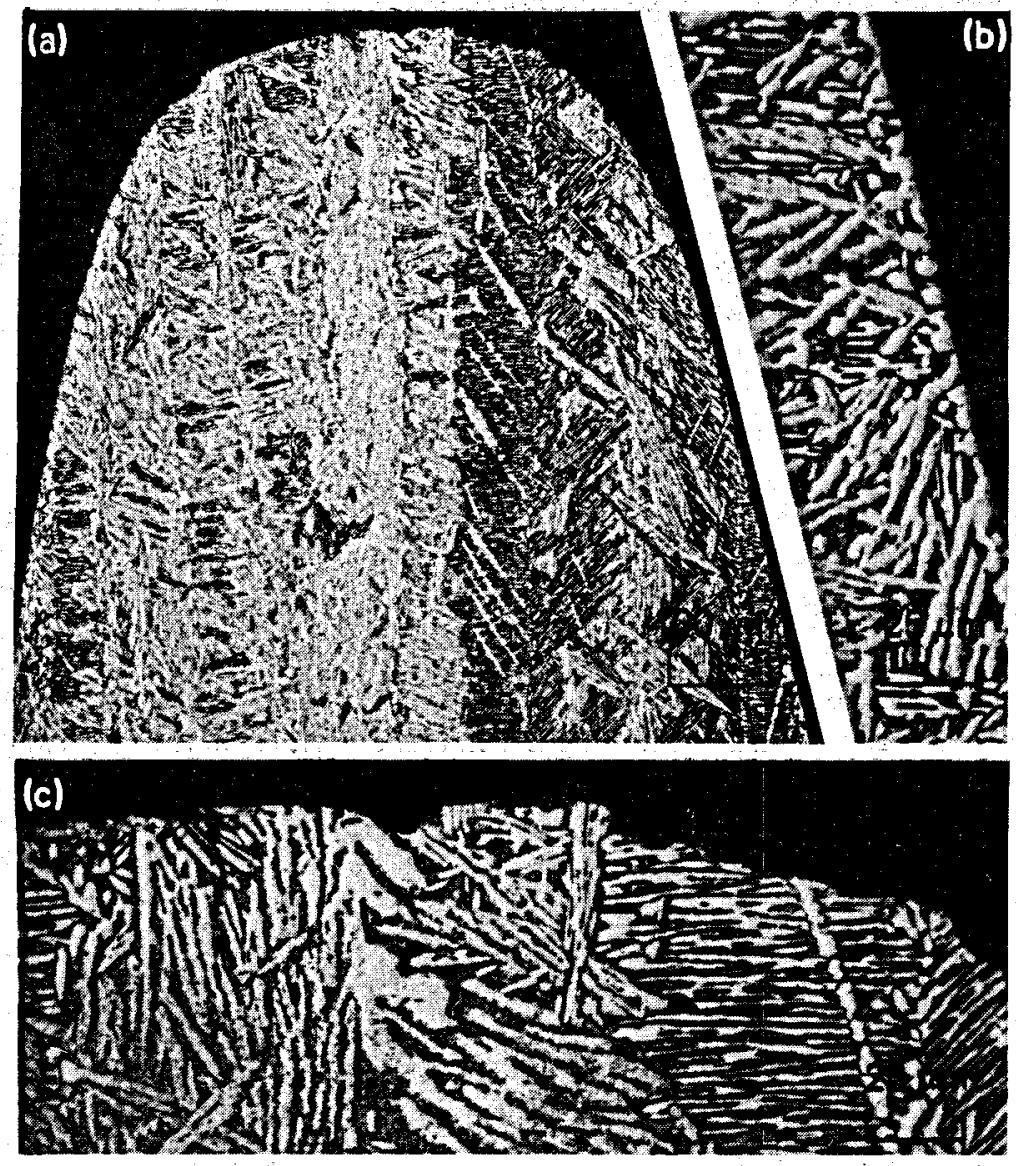

FIG. 7. Ti-6Al-4V wearblade $\left(R_{C} 36\right)$ exposed to $11 \%$-quality inlet brine for $60.5 \mathrm{~h}$, exhaust pH 2.4. (a) Tapered surface and tip after polishing and etching; higher magnification of tapered surface (b) and tip (c). 

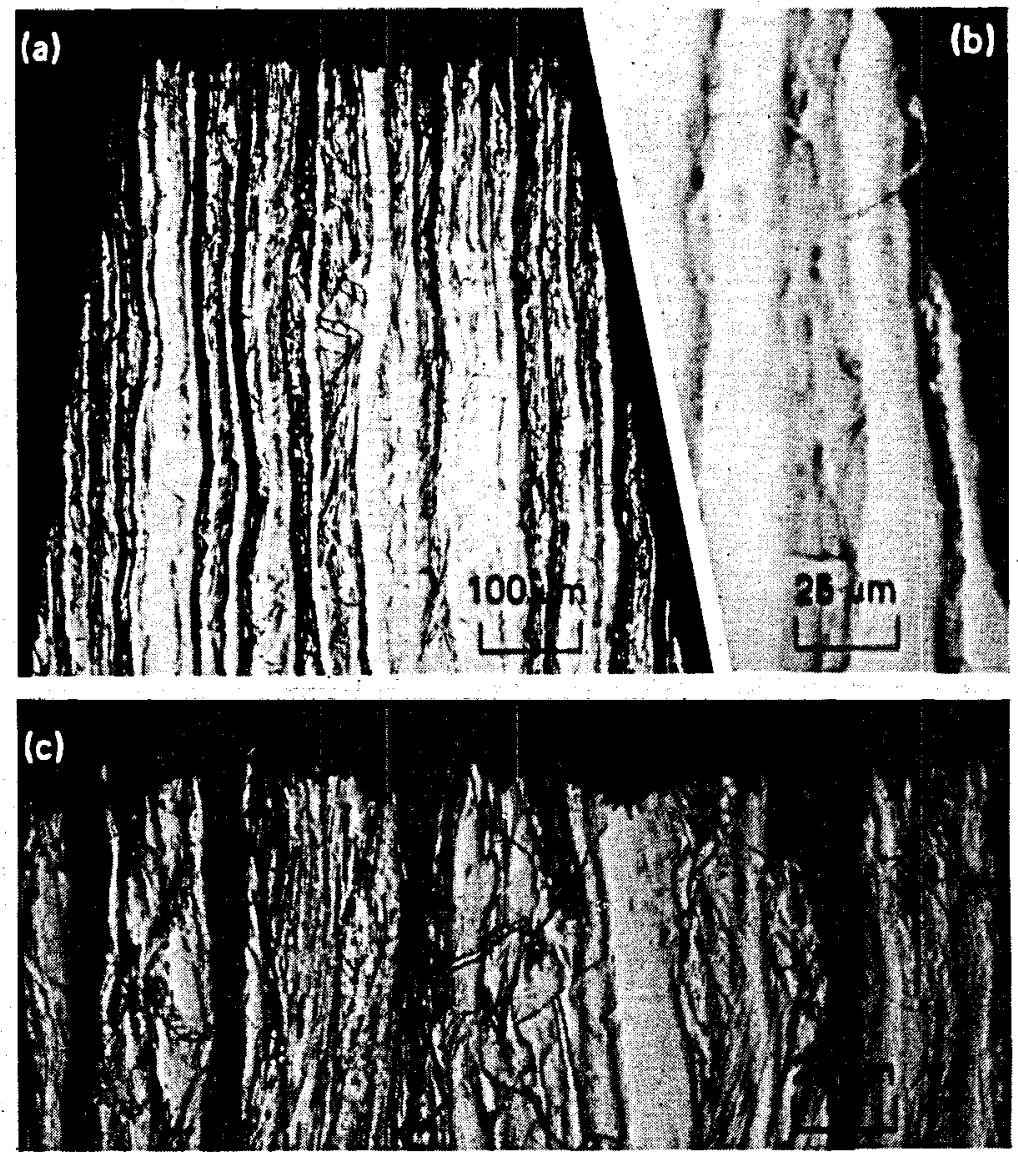

FIG. 8. Hastelloy $C-276$ wearblade $\left(R_{C} 46\right)$ exposed to $11 \%$-quality inlet brine for $49.5 \mathrm{~h}$ at exhaust pH 2.3. (a) Tapered surface and tip after polishing and etching; higher magnification of tapered surface (b) and tip (c).

erosion progressed by the formation and growth of individual microscopic cavities, with concomitant recession and flattening of the surface along the center of the tip. The arrows in Figs. 10c and 10d indicate the flat regions. The SEM views were taken at $90^{\circ}$ to the cross-section views, and therefore the cavities shown in Fig. 10b correspond to a cross section of the cavities in Fig. 10d. We suggest that the cavities merge to form new surfaces that are subsequently eroded by the formation of new cavities. For the two wearblades, we estimate the surface recession to be 3 and $70 \mu \mathrm{m}$ and the largest pit depths to be 2 and $60 \mu \mathrm{m}$, respectively. The ratios of the damage caused by the long- and short-time exposures are significantly greater than the ratios of the corresponding exposure times, suggesting either a long incubation period $(<20 \mathrm{~h})$ or, following an initial roughening of the surface, an acceleration of the rate of erosion during the interval between 20 and $120 \mathrm{~h}$.

In Figs. $10 \mathrm{~g}$ and $10 \mathrm{~h}$, the walls of the cavities appear to contain fine, submicron-size cavities about $1 \mu \mathrm{m}$ or less in diameter; the small cavities are irregular and somewhat angular, probably reflecting the shape of the impinging particles. In other cases (see below), the fine structure of the wall surfaces reveals a definite granular appearance with cavities and grains of approximately the same size shown in Fig. 10. 

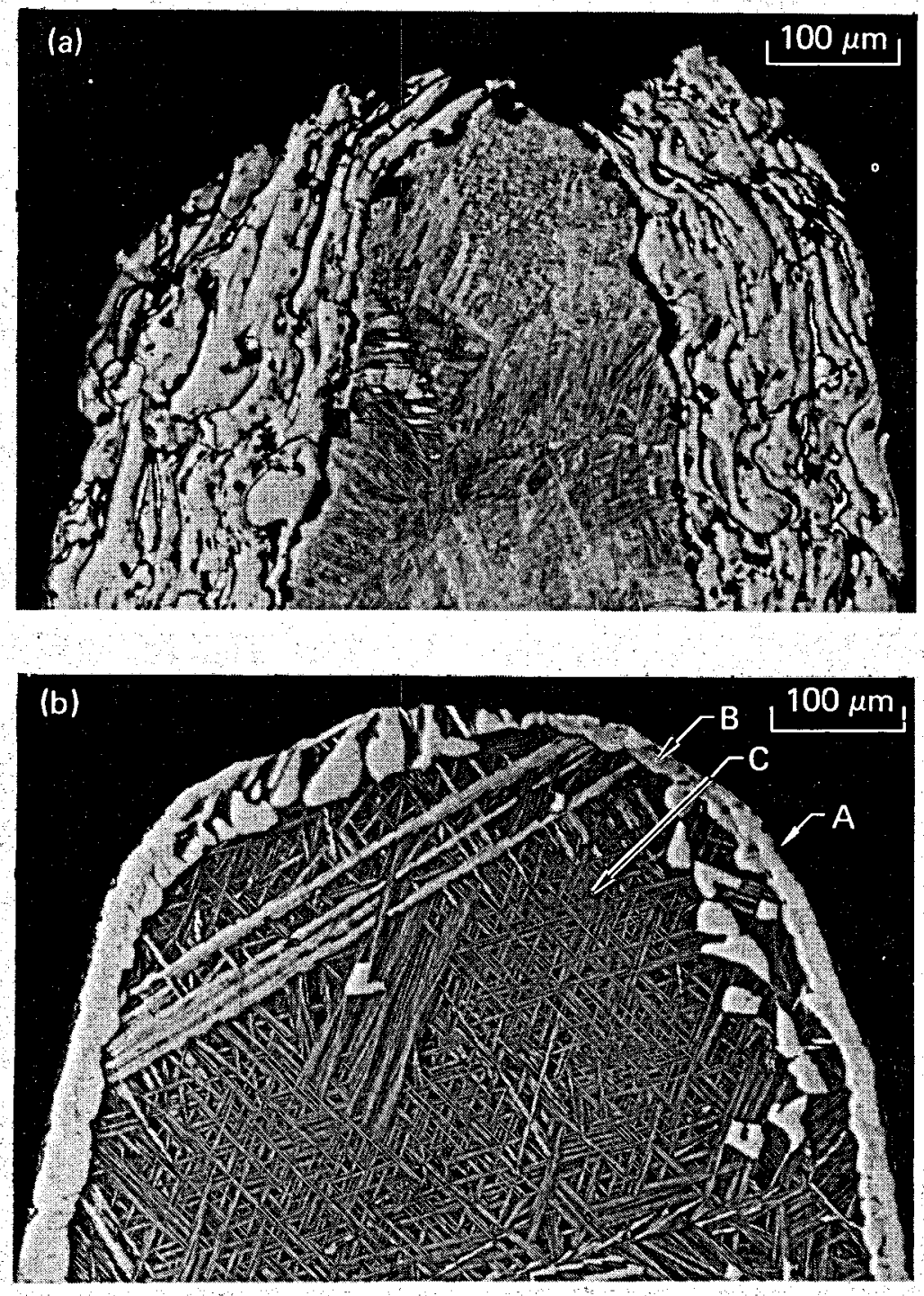

FIG. 9. (a) Ti-6Al-4V wearblade plasma-sprayed with 90Ta-10W ( $\left.R_{C} 45\right)$ exposed for $11.5 \mathrm{~h}$ to $11 \%$-quality inlet brine, exhaust pH 2.3. (b) Ti-6Al-4V carbonitrided wearblade exposed for $54.5 \mathrm{~h}$ to $33 \%$-quality inlet brine, exhaust pH 2.3 ; A, thin outer layer, $B$, intermediate layer, $\mathrm{C}$, diffusion zone in matrix. [The wearblade was exposed to $\mathrm{H}_{2} / \mathrm{N}_{2} / \mathrm{CH}_{4}$ at $1000 / 1025^{\circ} \mathrm{C}$ for $6.5 \mathrm{~h}$; the hardness $\left(R_{C} 37\right)$ reflects substrate hardness and not the thin case, which is probably DPH $\sim 1000]$. 

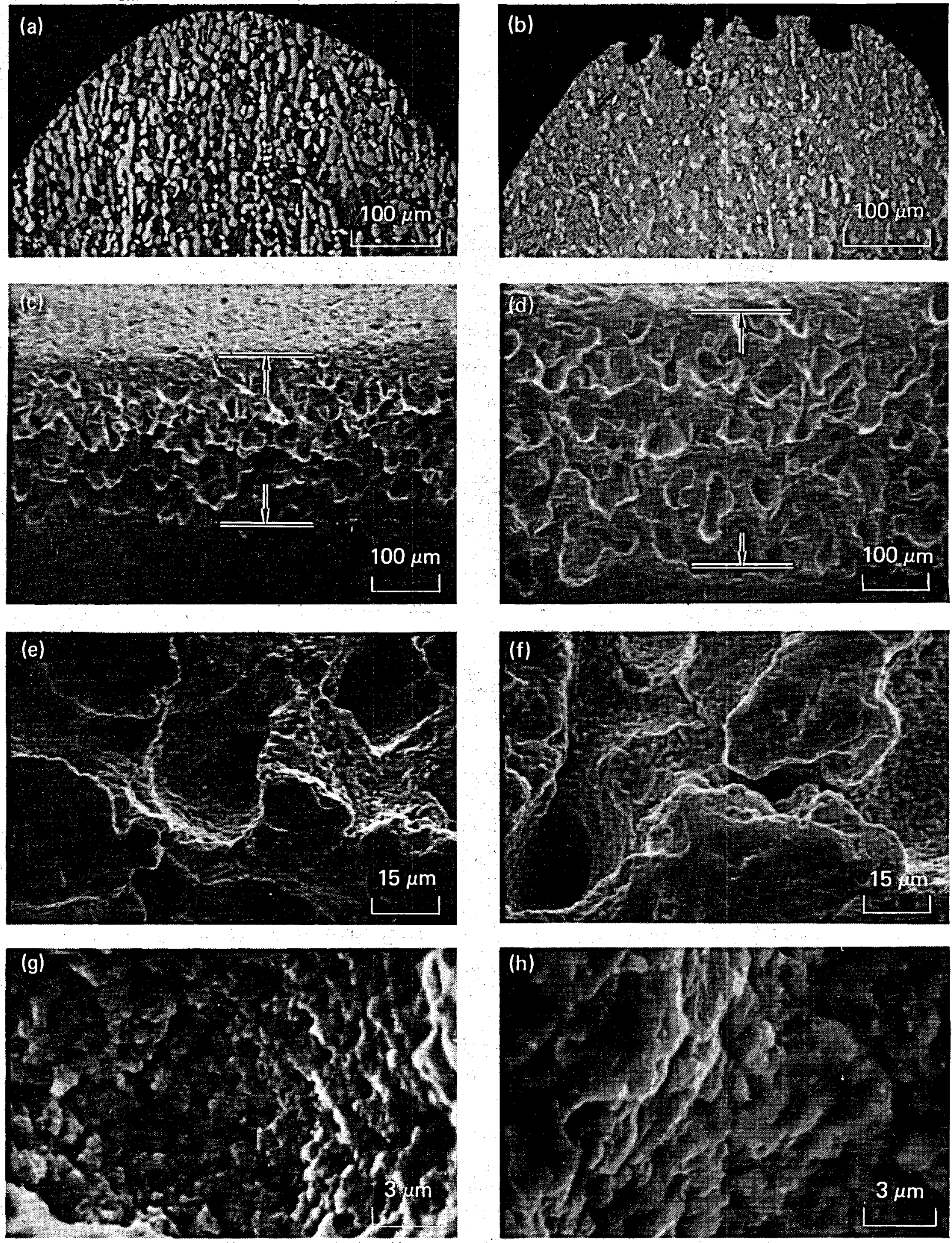

FIG. 10. Ti-6Al-4V-ELI wearblades exposed to 5\%-quality inlet brine, exhaust pH 3.4, for $20.1 \mathrm{~h}(\mathrm{a}, \mathrm{c}$, e, and $g$ ) and for $120.6 \mathrm{~h}\left(\mathrm{~b}, \mathrm{~d}, \mathrm{f}\right.$, and $\mathrm{h}$ ). Hardness of the two wearblades was $R_{C} 32$ and $R_{C} 34$, respectively. Arrows indicate the flattened tip region. 


\section{Microstructure and Hardness}

We thought that we could perhaps relate the erosion patterns to the microstructure, i.e., that the cavities in Fig. 10c could be related to the coarse primary $\alpha$ grains and those in Fig. $10 \mathrm{~g}$ to the fine, aged $\alpha^{\prime}$ martensite in the alloy. To examine this possibility, we compared three different microstructures of exposed wearblades that had been machined from Ti-6Al-4V ELI forgings and subjected to three different thermal treatments (heat treatments 6,7, and 8 in Table 5). Differences in the size of the original $\beta$ grains and in the relative proportions of primary $\alpha$ and $\alpha^{\prime}$ martensite were obtained with only minor variations in hardness ( $R_{C} 30$ to 33 ).

Four wearblades [prepared using heat treatments 6 (two wearblades), 7 , and 8 (one each)] were exposed to virtually identical conditions. We observed significant differences in the extent of degradation. Surprisingly, the greatest differences, both in the extent and, especially, in the morphology of the attacked surfaces, were found between the two identically heat-treated wearblades. Each wearblade had been exposed to $5 \%$ quality inlet brine in the same test station on two different days: one for $19.6 \mathrm{~h}$ at $\mathrm{pH} 3.0$, the other for $20.8 \mathrm{~h}$ at $\mathrm{pH} 3.5$.

Cross sections and SEM views of these two wearblades are shown in Fig. 11. Although both wearblades were degraded by the formation of cavities, some differences are apparent. In one case (Figs. $1 \mathrm{lc}$ and e), the complete surface was attacked; large cavities formed in a continuous field of small cavities or pits. In contrast, Figs. 11d and $11 \mathrm{f}$ show the surface of the second wearblade on which the original machining or polishing marks are still clearly visible, although deep cavities have developed. Cross-section views are consistent with these SEM observations: the surface of the tip of the first wearblade (Fig. 11a) has receded relatively uniformly whereas the second wearblade (Fig. $11 \mathrm{~b}$ ) clearly shows the formation of deep cavities within the original tip curvature. The differences in these two morphologies are difficult to explain; they suggest the possible overriding influence of unidentified environmental factors.

To examine the possible influence of hardness on degradation, we compared the behavior of annealed $\left(R_{C} 10\right)$ and cold-worked-and-aged $\left(R_{C} 43\right)$ Hastelloy $C-276$ wearblades. The two wearblades were exposed to $0 \%$ - and $5 \%$-quality inlet brines for 37 and $20.1 \mathrm{~h}$, respectively. We observed little difference in the extent of erosion damage and no difference in the morphology of the cavity walls. Figure 12 shows that the erosion cavities formed into erosion channels in these two exposed wearblades; the formation of such channels is probably associated with segregation of the alloy as indicated by the banding seen in Figs. 12a and 12b. The annealed wearblade was exposed almost twice as long as the hardened wearblade, but to less severe conditions (0\%- vs 5\%-quality inlet brine). Normally, more extensive erosion of the softer wearblade would be expected, but since only minor differences in the degree of degradation existed between these two wearblades, hardness did not appear to be an important criterion for erosion resistance, at least for this alloy under these conditions. As an alternative explanation, we suggest that corrosion must play an important role, minimizing the expected effect of hardness in this case.

The fine structure of the cavity walls (Figs. $12 \mathrm{e}$ and $\mathrm{f}$ ) consisted of angular-shaped grains. We suggest that these grains are "hills" between submicron cavities similar to those observed on exposed Ti-base alloy surfaces. Such angular-shaped grains were observed in all the $\mathrm{Ni}$ - and Co-base alloys. Differences between the cavity-wall morphologies of these alloys and the Ti-base alloys might have resulted from differences in the contribution of corrosive effects to erosion for the two groups of alloys.

Figure 13 shows cross sections of four $\mathrm{Co}$ - and $\mathrm{Ni}$-base wearblades exposed to $5 \%$-quality inlet brine for $20 \mathrm{~h}$. The alloys are arranged in this figure in order of decreasing relative resistance to degradation (from a through d). Quite clearly, the two Co-base alloys (Haynes 25 and Stellite 6B) suffered considerably less erosion than did the Co-Ni-base and Ni-base alloys, even though Stellite 6B, a Co-base alloy, is the softest of the four. Although the two Co-base alloys differ significantly in hardness $\left(R_{C} 51\right.$ vs $\left.R_{C} 37\right)$ they differ only slightly in damage, again suggesting that hardness does not influence erosion rates in this case.

Generally, it is expected that Mo would reduce any corrosive contribution to the erosion of these alloys in the acidic reducing brines. Both MP35N $\left(R_{C} 46\right)$ and Hastelloy $C-276\left(R_{C} 43\right)$ (Figs. 13c and d) contain significant amounts of Mo: 10 and $16 \%$, respectively; Stellite $6 \mathrm{~B}$ contains $1.5 \%$ Mo maximum, and Haynes 25 contains none. However, a key factor of erosion in a corrosive environment is repassivation kinetics, and Mo might have an adverse effect on such kinetics. Alternatively, the high Co content of the two 

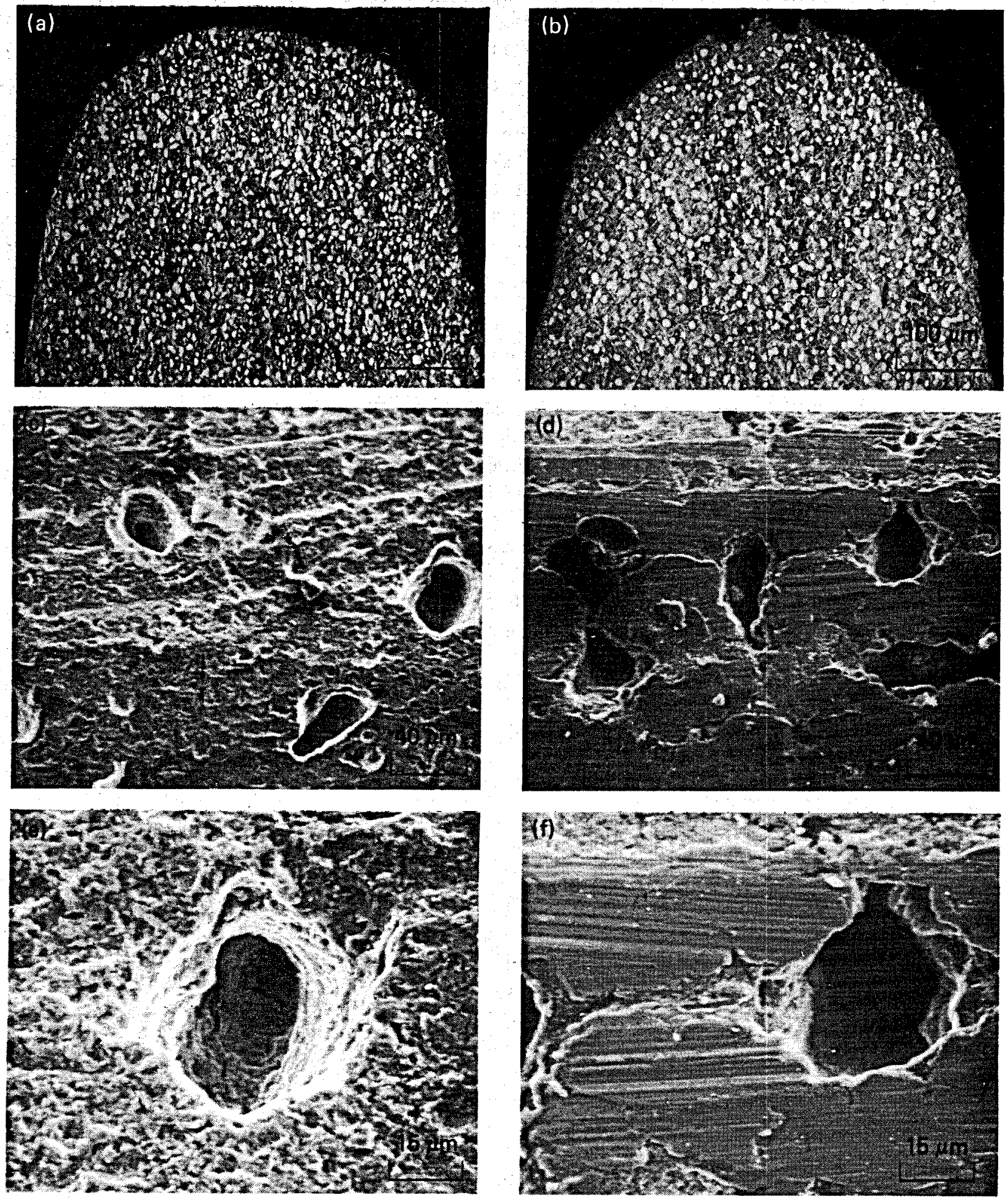

FIG. 11. Two identically heat-treated wearblades exposed to $5 \%$-quality inlet brine on two different days (a, c, and e) for $19.6 \mathrm{~h}$, exhaust $\mathrm{pH} 3.0\left(\mathrm{R}_{\mathrm{C}} 32\right)$ and $(\mathrm{b}, \mathrm{d}$, and $\mathrm{f})$ for $20.8 \mathrm{~h}$, exhaust $\mathrm{pH} 3.5\left(\mathrm{R}_{\mathrm{C}} 33\right)$. 



FIG. 12. Hastelloy $C-276$ wearblades: (a, c, and e) mill-annealed condition $\left(R_{C} 10\right.$ ), exposed for $37 \mathrm{~h}$ to $0 \%$ quality inlet brine, exhaust $\mathrm{pH} 2.9 ;(\mathrm{b}, \mathrm{d}$, and $\mathrm{f}) 60 \%$ cold rolled and aged $100 \mathrm{~h}$ at $500^{\circ} \mathrm{C}\left(\mathrm{R}_{\mathrm{C}} 43\right)$, exposed for $20.1 \mathrm{~h}$ to $5 \%$-quality inlet brine, exhaust $\mathrm{pH} 3.4$. 



FIG. 13. Cross sections of four wearblades exposed for about $20 \mathrm{~h}$ to $5 \%$-quality inlet brine: (a) Haynes 25 (33\% cold rolled $+100 \mathrm{~h}$ at $500^{\circ} \mathrm{C}, \mathrm{R}_{\mathrm{C}} 51$ ), exposed for $20.1 \mathrm{~h}$, exhaust pH 3.7; (b) Stellite $6 \mathrm{~B}$ (mill annealed + $11 \%$ cold rolled, $R_{C} 37$ ), exposed for $18.5 \mathrm{~h}$, exhaust pH 3.7 ; (c) MP35N ( $50 \%$ cold rolled $+4 \mathrm{~h}$ at $538^{\circ} \mathrm{C}$, $R_{C} 46$ ), exposed for 20.0 h, exhaust pH 3.6; (d) Hastelloy C-276 (60\% cold rolled +100 h at $\left.500^{\circ} \mathrm{C}, R_{C} 43\right)$, exposed for $20.1 \mathrm{~h}$, exhaust pH 3.4 .

Haynes alloys in contrast to the high $\mathrm{Ni}$ content in the C-276 alloy might be a contributing factor; contradicting this suggestion, however, is the fact that MP35N contains 35\% of both Ni and $\mathrm{Co}$, yet it suffered severe attack. The $\mathrm{Cr}$ contents range from $16 \%$ for C-276 to $30 \%$ for Stellite $6 \mathrm{~B}$; however, both Haynes 25 and MP35N contain about $20 \% \mathrm{Cr}$.

Figure 14 shows the four wearblades prior to sectioning. Although these wearblades were exposed under almost identical controlled conditions in the same test series, there are differences in the patterns formed both in the central region exposed to the direct nozzle exhaust and in the peripheral regions, caused largely by splashback from the elbow chamber. Such differences must arise from variations in brine characteristics, such as composition, $\mathrm{pH}$, velocity, amounts of flashing, etc. The extent to which these variations affected the degradation of the wearblades is not clear. The results, however, do suggest that hardness plays a secondary role to some other factor (probably corrosion resistance) in determining the relative resistance of these Co- and Ni-base alloys to degradation in acidic, highly mineralized, high-velocity brines.

Examination of Table 2 suggests that hardness may exert a minor effect on the erosion resistance of Ti-base alloys. If exposure time is considered, the Ti-0.3Mo- $0.8 \mathrm{Ni}$ wearblade, which has the lowest hardness value $\left(R_{C} 6\right)$, showed the least resistance to degradation (Fig. 15). The erosion morphology resembled that observed for most of the Ti-base alloys; cavities and surface recession are present, but the cavities here are more numerous and tend to be interconnected. In contrast, the cavities in the harder Ti-base alloys were usually separated. The Ti-6Al-6V-2Sn alloy with the highest hardness $\left(R_{C} 43\right)$ showed the least degradation. As we point out in the next section, however, the exposed wearblade of this latter alloy (Fig. 18) was covered with a tenaceous silica-rich scale, which may explain its relatively high resistance to erosion. The hardness values of 



FIG. 14. Four exposed wearblades shown in .Fig. 13 prior to sectioning. (a) Haynes 25, (b) Stellite 6B, (c) MP35N, (d) Hastelloy-276. 

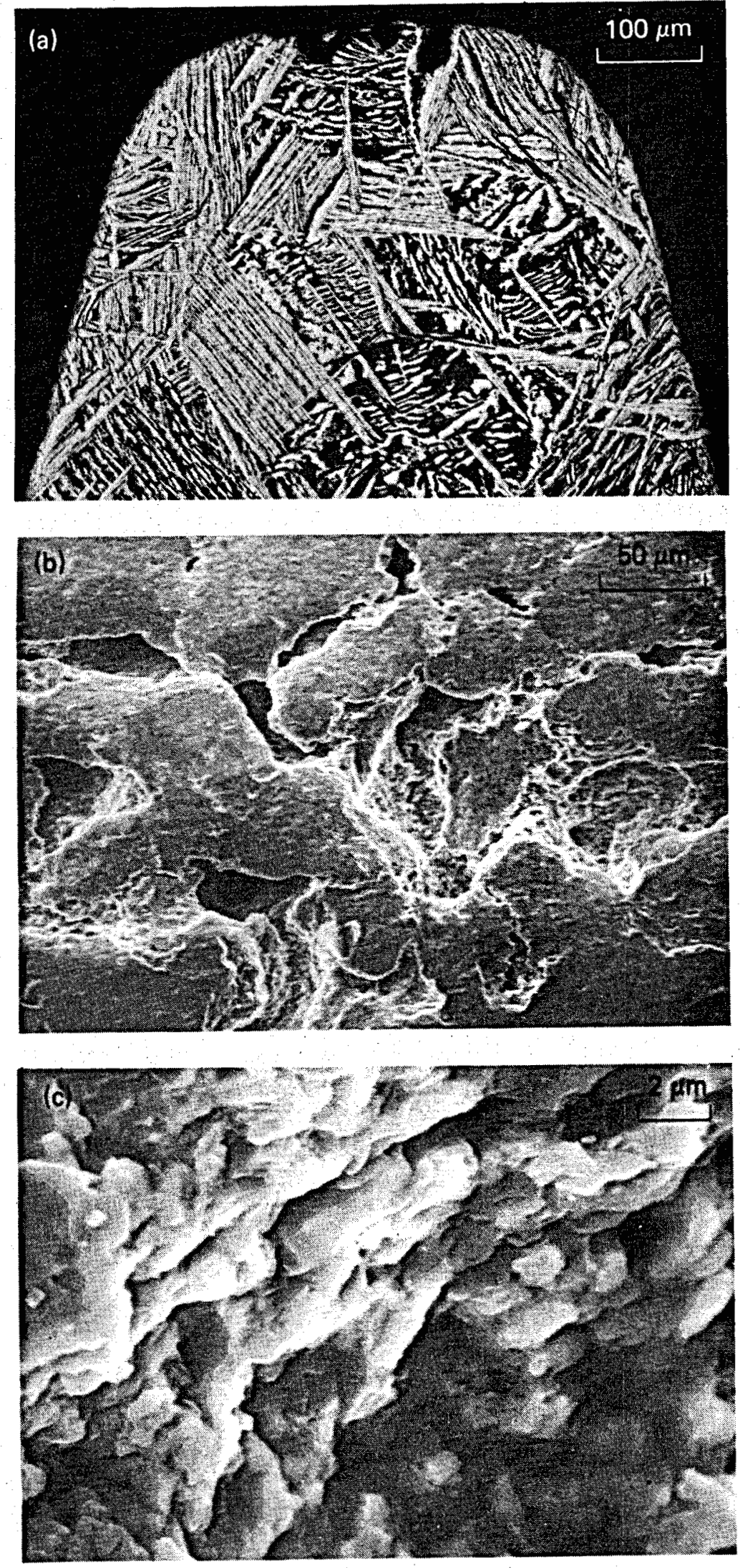

FIG. 15. Ti-0.3Mo-0.8 $\mathrm{Ni}$ wearblade $\left(R_{C} 6\right)$ exposed for $25 \mathrm{~h}$ to $0 \%$-quality inlet brine, exhaust pH 3.9. (a) Deep erosion cavities and surface recession. SEM views (b) and (c) indicate extensive formation of both "large" and "small" cavities. 
the majority of the Ti-base alloys fall within the range of $R_{C} 30-36$, and examination of Table 2 shows that variations in degradation unrelated to hardness occur within this group. Furthermore, the variations observed cannot be attributed unequivocally to differences in either acidification or brine quality, the only two controlled variables (in addition to exposure time).

\section{Influence of Scale Deposits}

The possibility that scale deposits offer protection can be inferred from Fig. 16, which shows views of a Ti-6Al-4V-ELI wearblade $\left(R_{C} 34\right)$ exposed for $20.1 \mathrm{~h}$ to unacidified $5 \%$-quality inlet brine (exhaust $\mathrm{pH}$ 5.6). The scale deposited during the test had been removed before examination. This wearblade should be compared with one made of the same alloy that was exposed to acidified brine for $20.1 \mathrm{~h}$ (Figs. 10a, c, e, and g). In the SEM views (Figs. 16b and c), a number of relatively small and shallow cavities are visible. It appears that, during the initial stages of scale deposition, the impact of the precipitated solids caused relatively uniform but shallow erosion along the whole tip surface. Rapid build-up of scale, however, soon arrested this erosion. The fine cavity-wall structure mentioned earlier is clearly visible along the whole surface (Fig. 16d).

A number of EDS analyses of the Ti-6Al-4V-ELI wearblade verified that we had removed the scale completely. The spectrum in Fig. 17a was representative of those taken along the surface from which the scale had been scraped and shows only the presence of $\mathrm{Ti}, \mathrm{Al}$, and V. Figure $17 \mathrm{~b}$ shows a spectrum of an area where the scale had not been dislodged. The main peaks in this spectrum correspond to $\mathrm{Cu}$ and $\mathrm{S}$, indicating the presence of CuS; also detected are lesser quantities of $\mathrm{Si}, \mathrm{Cl}, \mathrm{Ag}$, and $\mathrm{K}$ in addition to $\mathrm{Ti}, \mathrm{Al}$, and $\mathrm{V}$ of the alloy. The spectrum did not vary significantly at different points along the scale deposit.

The protective nature of scale was also illustrated for two wearblades, a Ti-6Al-6V-2Sn and a Ti-6Al$4 \mathrm{~V}$ wearblade, on which scale had formed during an acidification test. Scale formation was probably due to one or more $\mathrm{pH}$ excursions to higher values during the run. Both wearblades experienced relatively little erosion, and their erosion patterns differed from those observed on other wearblades. Figure 18 contains a crosssection view (a), four SEM views (b-e), and two EDS spectra (f-g) for the Ti-6Al-6V-2Sn wearblade $\left(R_{C} 43\right)$ exposed for $20 \mathrm{~h}$ to $5 \%$-quality inlet brine (exhaust pH 3.8). Views of regions A and B (in Figs. 18a and b) are shown at greater magnification in Figs. $18 \mathrm{c}-\mathrm{d}$ and $18 \mathrm{e}$, respectively; the corresponding spectra are shown in Figs. $18 \mathrm{f}$ and $18 \mathrm{~g}$.

Two types of erosion patterns characterized by these two regions are apparent along the contiguous surfaces A and B shown in Fig. 18b. The surface in region A exhibits a flowing "hill-and-valley" morphology reminiscent of moguls on a ski slope. (A. V. Levy of the University of California, Lawrence Berkeley Laboratory, Berkeley, California, has suggested that the term "mogul" be used to describe this type of surface.) This morphology suggests that plastic deformation by an extrusion-like process has occurred, but the surface recession (i.e., erosion) was very minimal here, and no erosion pits were apparent. An EDS analysis along this region indicated the presence of a continuous surface layer high in $\mathrm{Si}$ and containing other elements, mainly $\mathrm{Cu}$ and $\mathrm{S}$. We were unable to remove the film with our standardized cleaning technique. We suggest that the moguls were probably associated with the mode of deposition of this adherent Si-rich scale. In contrast, where erosion pits were observed, as in region B, the EDS spectrum (Fig. 18g) showed only the elements present in the alloy. The presence of shallow pits and evidence of original machining marks (Fig. 1.8e) indicated that this region showed good resistance to erosion. It is likely that scale deposits had also formed here but were less tenacious and more readily removed.

Figure 19 shows three SEM views and two EDS spectra of the Ti-6Al-4V wearblade $\left(R_{C} 35\right)$ that also exhibited relatively minor erosion. It was exposed for $22.5 \mathrm{~h}$ to $0 \%$-quality inlet brine (exhaust pH 3.7). At low magnification (Fig. 19a), the whole tip appeared to have the mogul hill-and-valley structure. The EDS analyses invariably showed high Si content and only very minor amounts of other elements (Fig. 19d). At high magnification, two slightly different morphologies became apparent; one was more typical of the mogul structure (Fig. 19b) and the other suggested plates or sheets protruding from the surface (Fig. 19c). Both areas occasionally contained globular particles; the one indicated by the arrow in Fig. 19c contained significant amounts of $\mathrm{Ca}, \mathrm{Fe}$, and $\mathrm{Cu}$ (Fig. 19e). The analyses for different particles varied, but all were high in $\mathrm{Fe}$ and 



FIG. 16. Ti-6Al-4V-ELI wearblade $\left(R_{C} 34\right)$ exposed for $\mathbf{2 0 . 1} \mathrm{h}$ to unacidified $5 \%$-quality inlet brine, exhaust pH 5.6. Large cavities are absent. 

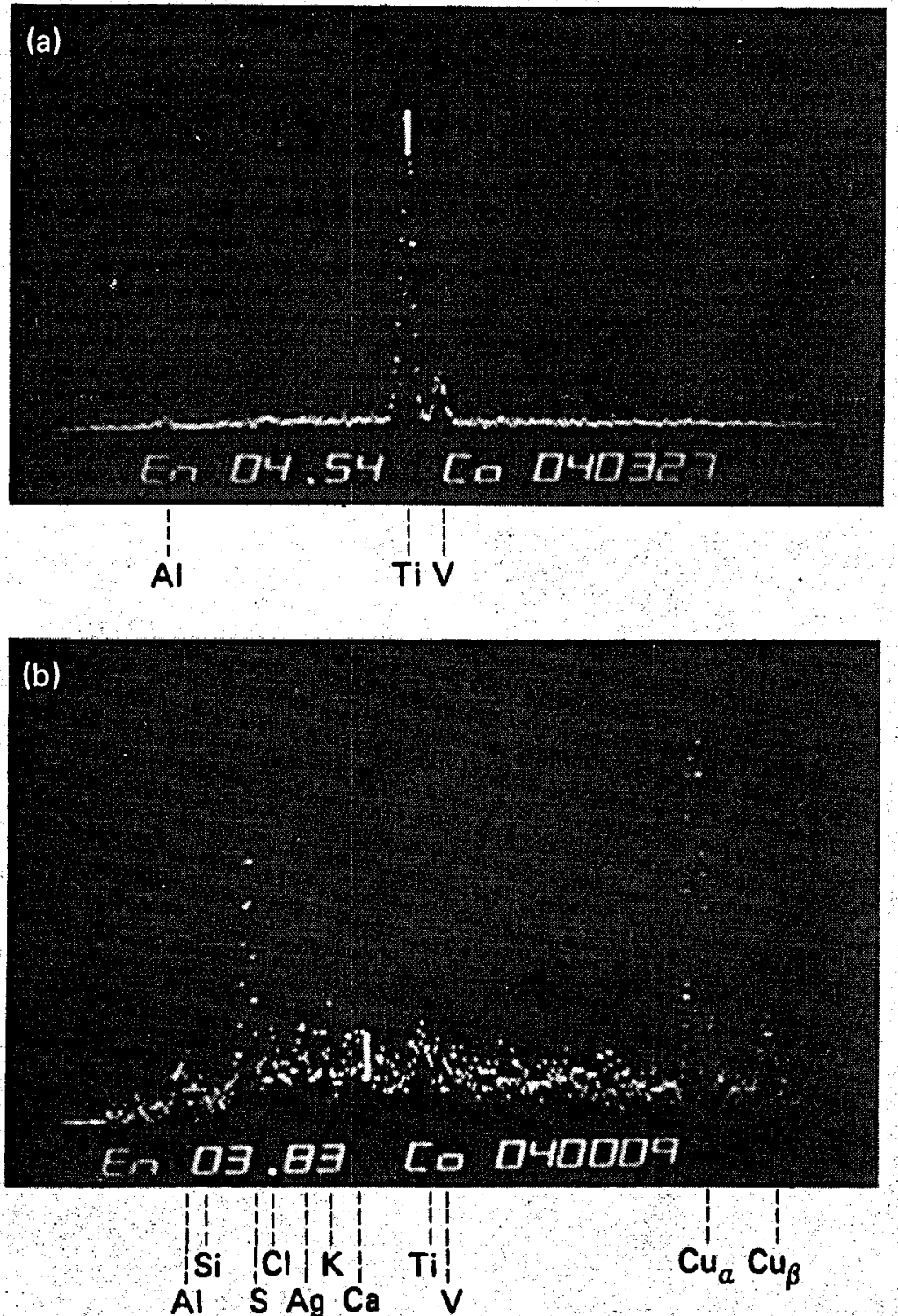

FIG. 17. EDS spectra of the wearblade tip shown in Fig. 16 that are typical of regions where scale had been scraped off for examination (a) and of regions where scale remained (b). 



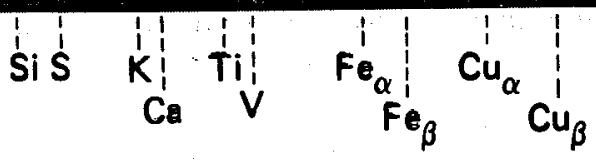

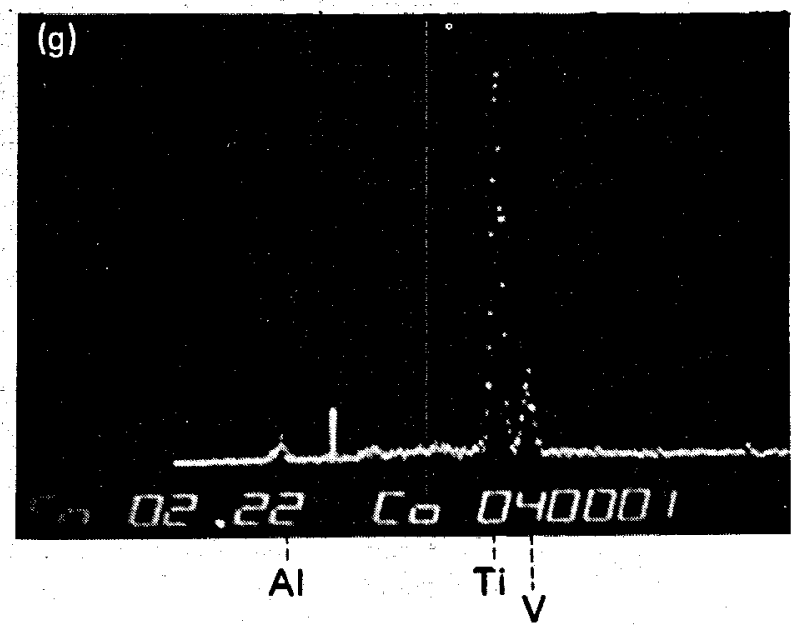

FIG. 18. Ti-6Al-6V-2Sn wearblade ( $\left.R_{C} 43\right)$ exposed for $20 \mathrm{~h}$ to $5 \%$-quality inlet brine, exhaust $\mathrm{pH}$ 3.8. Cross section view (a) and SEM view (b) show region A, covered with a Si-rich scale, and region $B$, without scale. SEM views at greater magnification show regions $A$ (c and $d)$ and $B(e)$. EDS spectra of regions $A$ and $B$ are shown in (f) and (g), respectively. 

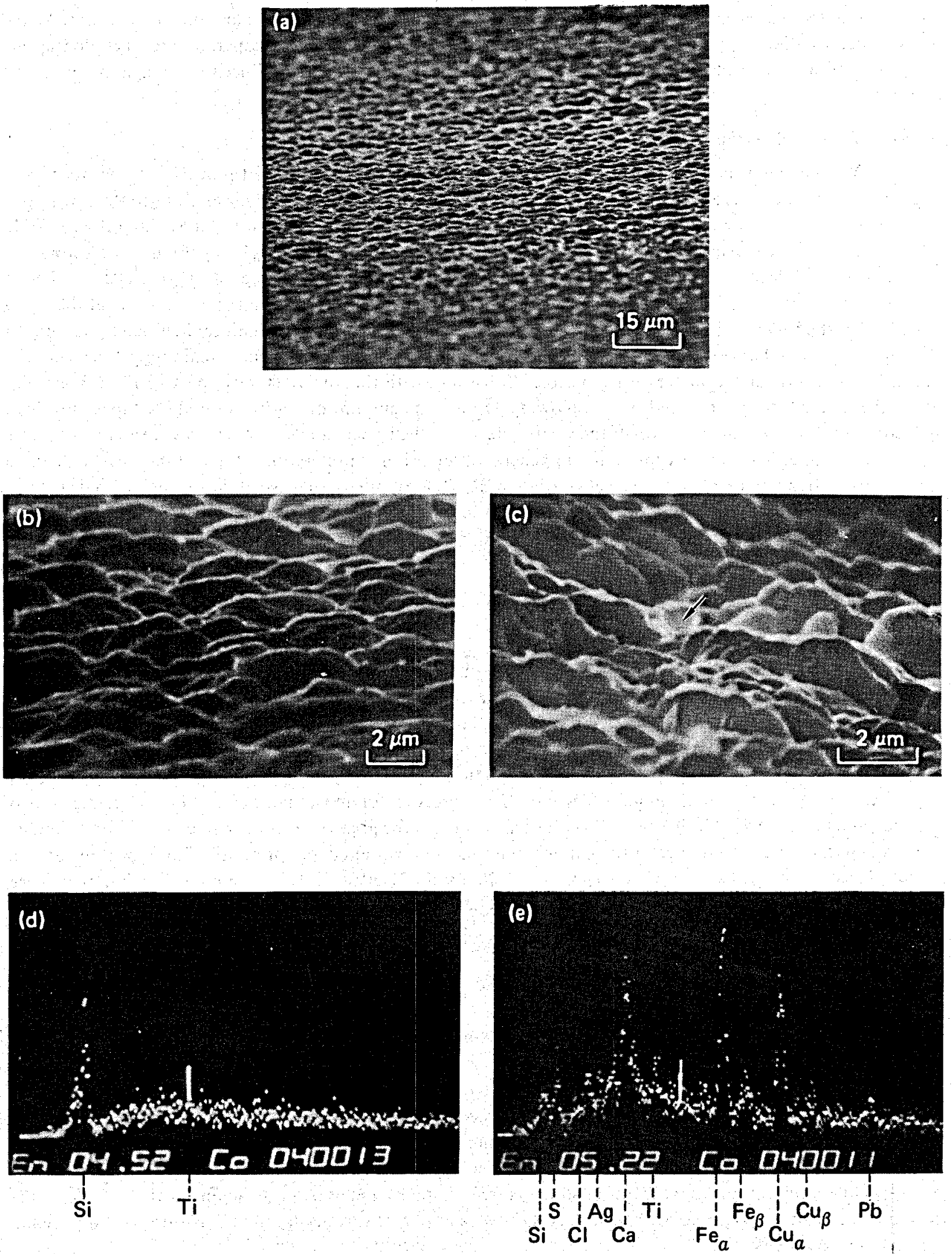

FIG. 19. Ti-6AI-4V wearblade $\left(R_{C} 35\right)$ exposed for 22.5 h to $0 \%$-quality inlet brine, exhaust pH 3.7. (a) Low magnification SEM view; (b and c) high magnification views of two different areas; (d) typical EDS spectrum of surface; (e) EDS spectrum of particle indicated by arrow in (c). 
also contained S. It appears that a tenacious Si-rich scale layer was deposited that subsequently entrapped particles of metal sulfides; the latter, however, were largely removed by the cleaning operation for metallographic analysis. The above results suggest that some protection is offered by the Si-rich layer against erosion/ corrosion.

\section{Erosion of Tapered Surfaces}

We indicated earlier that erosion was usually much more severe at the tip of the leading wearblade edge than along the tapered surfaces, and, because of this, we usually restricted our analysis to the tip region. Figure 20 exemplifies the type of morphology observed along the tapered surface of a Stellite 6B wearblade $\left(R_{C} 37\right)$ that had been exposed for $18.5 \mathrm{~h}$ to $5 \%$ quality inlet brine (exhaust $\mathrm{pH} 3.7$ ). Figure 20a shows the tapered surface A leading into the curvature of the tip surface B (light etching region). Figure 20c is a view at the junction of these two surfaces at higher magnification that shows a transition from "cavities" at the tip to "gouges" at the beginning of the tapered section. Figure $20 \mathrm{~b}$ shows numerous small cavities in a tip region. In the taper region $500 \mu \mathrm{m}$ below the edge of the tip region (Fig. 20d), the original machining gouges running parallel to the flow direction are clearly visible. Consistent with the low angle of impact $(0.17$ rad), erosion along the tapered surface resulted from a plowing action. The amount of degradation at the taper, however, was considerably less than at the tip of the wearblade where the impact angle is generally considerably larger.

Figure 21 shows an exception to our general observation of preferential attack at the wearblade tip: a quenched-and-tempered 2.2Cr-1 Mo steel wearblade $\left(R_{C} 21\right)$ exhibited extensive attack at the tapered surfaces as well as at the tip. The wearblade, exposed for $37 \mathrm{~h}$ to $0 \%$-quality inlet brine (exhaust $\mathrm{pH} 2.6$ ), was covered with a thick layer of corrosion product and scale (see Fig. 4b). Severe degradation expected for this material was observed.

\section{SCC SPECIMENS}

Figures 22-26 contain photomicrographs taken of longitudinal-thickness surfaces of SCC specimens. The notations " $F$ " and " $R$ " refer to front- and rear-mounted specimens (Fig. 4c). The figures show only tensile-stressed surfaces, but we examined both tensile and compressive surfaces. We examined specimens for evidence of SCC, erosion cavities, and corrosion. Eighty-seven specimens were exposed, 80 in pairs (front and rear specimens) and 7 individually (front only). Formation of cavities by erosion or corrosion-assisted erosion proved to be the predominant mode of degradation observed for most specimens. Many specimens also showed evidence of SCC. The Ti-base alloys generally showed the greatest resistance to erosion/corrosion attack. We characterized the degree of such attack in terms of maximum depth of cavities falling within various ranges: A, no attack; B, $\leqslant 3 \mu \mathrm{m} ; \mathrm{C}, 4-10 \mu \mathrm{m} ; \mathrm{D}, 11-20 \mu \mathrm{m} ; \mathrm{E}, 21-50 \mu \mathrm{m}$; and $\mathrm{F},>50 \mu \mathrm{m}$. Crack depths were excluded from this classification; the presence or absence of cracks either in or outside of the SCC notch was noted (several specimens were not notched, however). These observations for $\mathrm{Ti}$-base and for $\mathrm{Fe}-\mathrm{Ni}$, , and $\mathrm{Cr}-$ base alloys are summarized in Tables 3 and 4, respectively. In these tables, we distinguish the front-mounted specimens exposed to the direct nozzle exhaust from the protected rear-mounted specimens in order to separate the effects of erosion from corrosion.

We included one pair of Ti-8Al-1Mo-1V specimens in each of the first two test series because this material is known to exhibit SCC in aqueous chlorides. ${ }^{5,7}$ As expected, numerous cracks up to about $50 \mu \mathrm{m}$ deep developed along the entire tensile surface of these four specimens and at the base of the SCC notch in the two front specimens. Figure 22 contains micrographs of several Ti-base alloys and illustrates both SCC and erosion. Figure 22a shows stress-corrosion cracks along the tensile surface of a Ti-8Al-1Mo-1 V specimen. An example of SCC at the notch is shown in Figs. $22 \mathrm{~b}-\mathrm{c}$ for a Ti-6Al-4V specimen. It should be noted that for the latter specimen, the surface away from the notch is free of cracks and erosion. Cracking at the notch appears to be predominantly intergranular. Figures $22 \mathrm{~d}$-f show examples of various degrees of erosion typically seen in the Ti-base specimens.

Table 8 summarizes the SCC results and lists the number of specimens of each alloy tested and those that showed cracks, either in or outside of the notch. Although Ti-6Al-4V-ELI samples exhibited less susceptibility to SCC than did those of Ti-6Al-4V; the latter alloy was more resistant to erosion than the former 

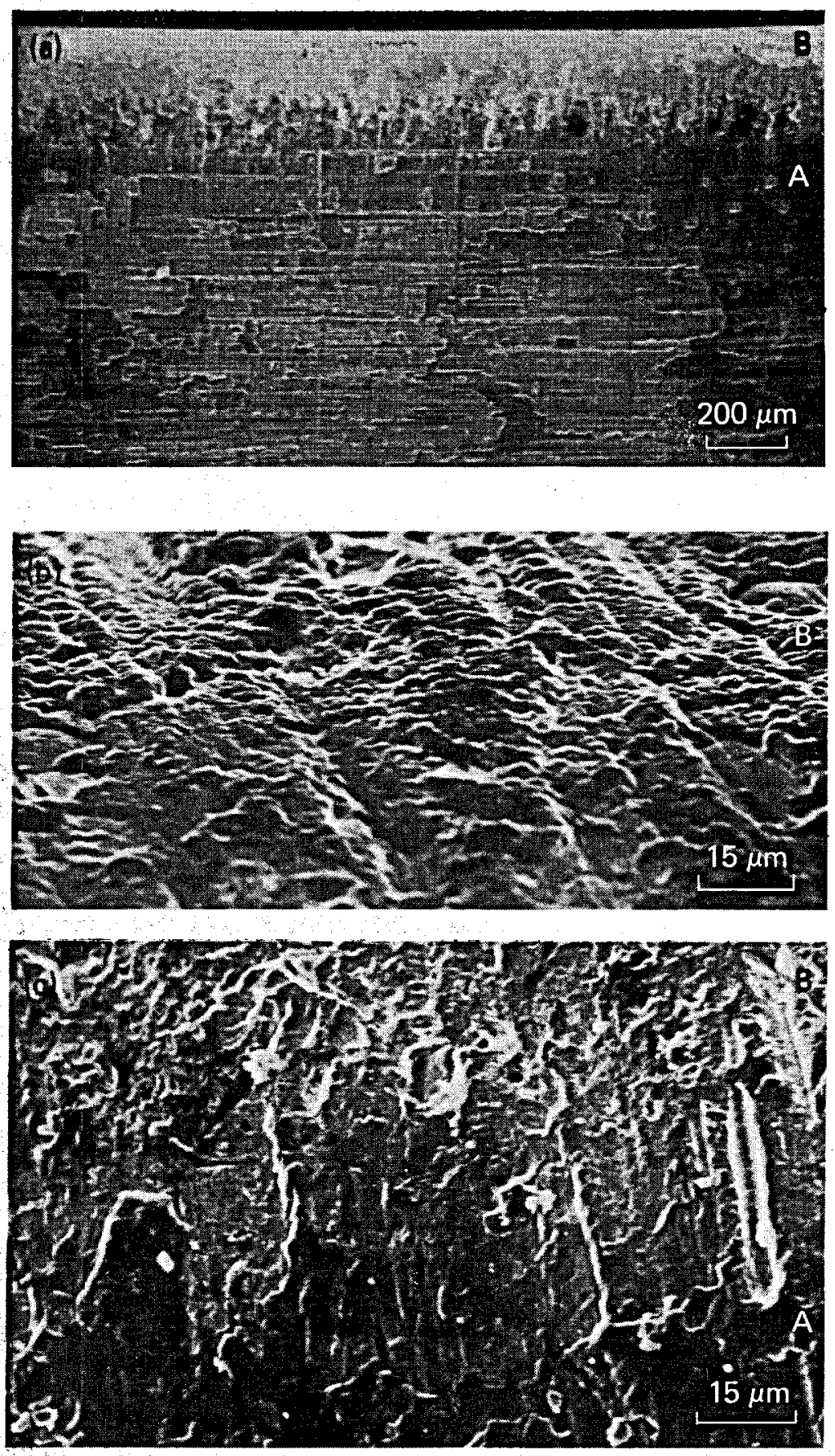

FIG. 20. Stellite 6B wearblade ( $R_{C} 37$ ) exposed for $18.5 \mathrm{~h}$ to $5 \%$ quality inlet brine, exhaust pH 3.7. SEM views were taken with tapered surface oriented horizontally. (a) Tapered surface A leading into tip B. (b) Region B. (c) Interface area of regions $A$ and $B$. (d) Region A.

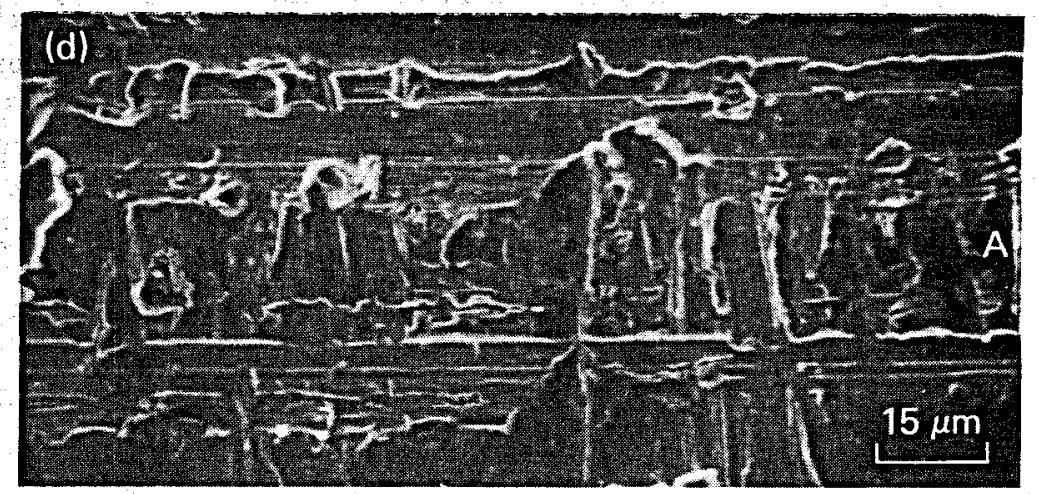




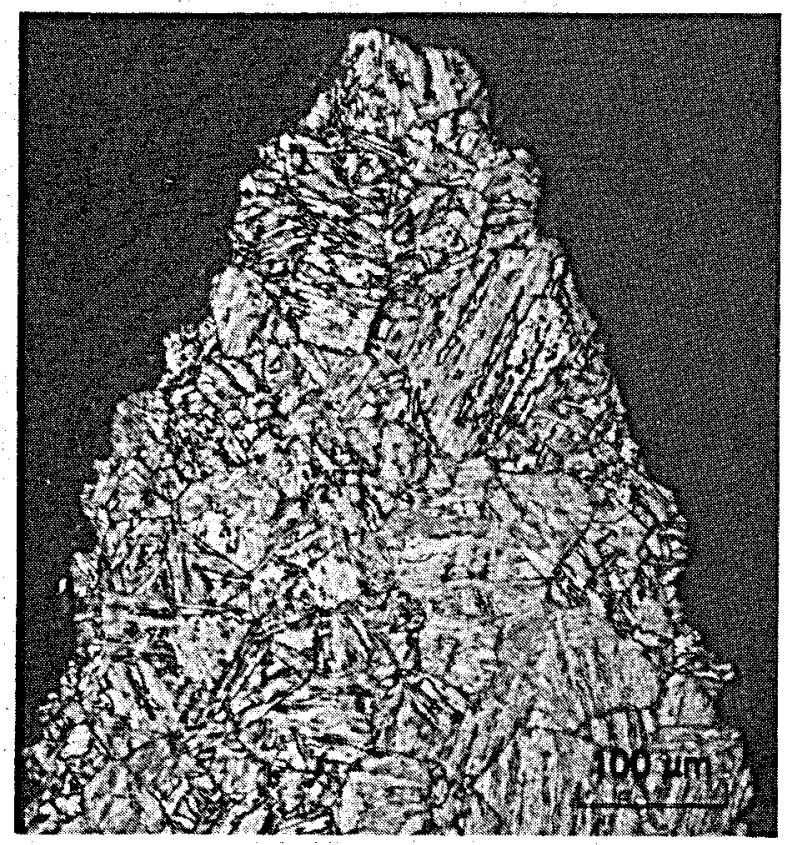

FIG. 21. Cross section of leading edge of a quenched-and-tempered $2.2 \mathrm{Cr}$ - $1 \mathrm{Mo}$ steel wearblade $\left(R_{C} 21\right)$ showing severe erosion/corrosion of both tip and tapered surfaces. The wearblade was exposed for 37 h to $0 \%$-quality inlet brine, exhaust pH 2.6. 

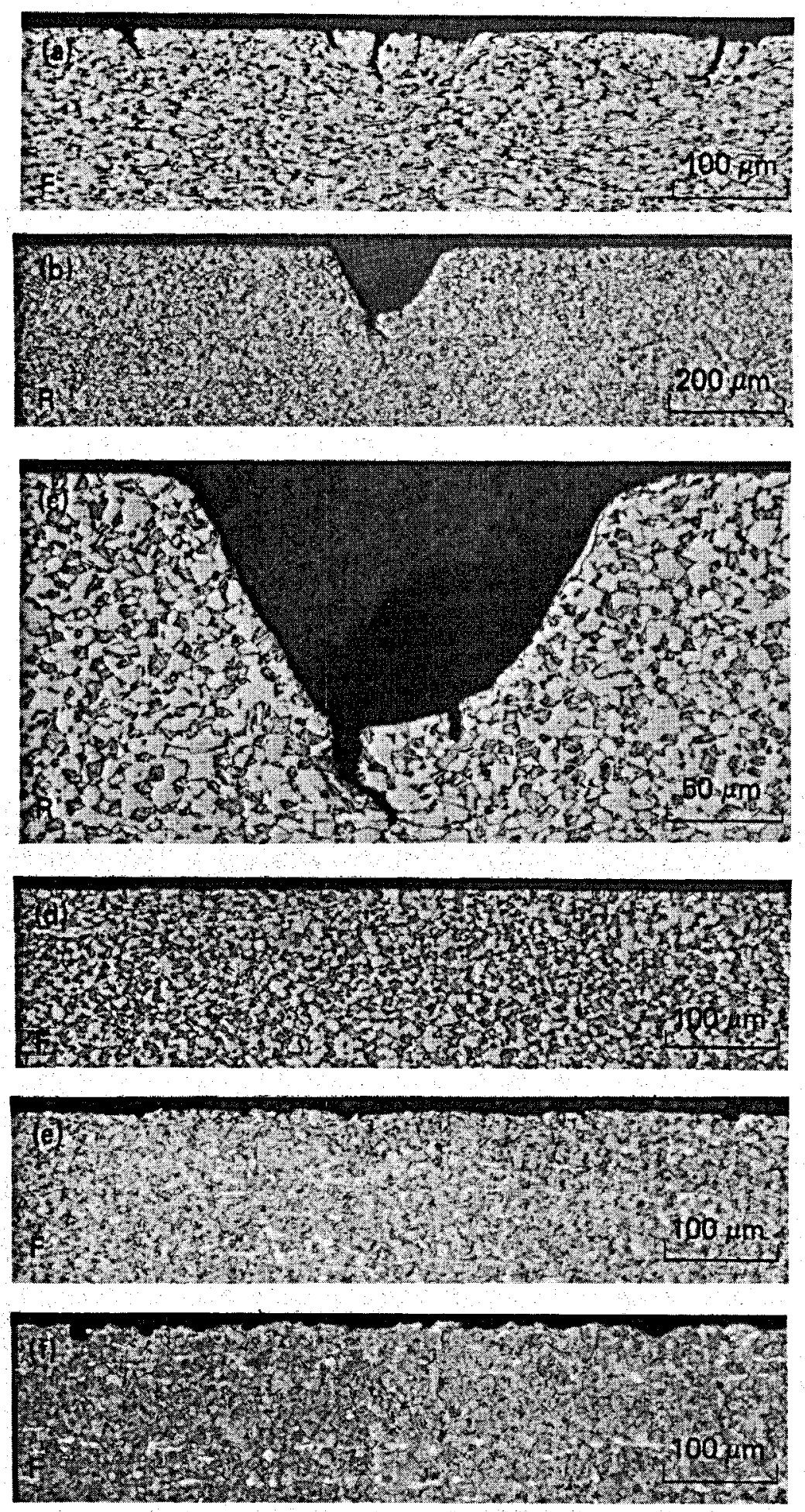

FIG. 22. Examples of exposed Ti-base SCC specimens: (a) Ti-8AIIMo-1V (DPH 345) exposed for $25 \mathrm{~h}$ to $0 \%$-quality inlet brine, exhaust pH 3.9; (b, c, and d) Ti-6Al-4V (DPH 334) exposed for $110.5 \mathrm{~h}$ to $0 \%$-quality inlet brine, exhaust pH 3.0; (e) Ti-6Al-4V (DPH 342) exposed for $60.5 \mathrm{~h}$ to $11 \%$-quality inlet brine, exhaust pH 2.4; (f) Ti-6Al-4V-ELI (DPH 336) exposed for $60.5 \mathrm{~h}$ to $11 \%$ quality inlet brine, exhaust pH 2.4. The letters $F$ and $\mathrm{R}$ refer to front and rear specimens, respectively. 

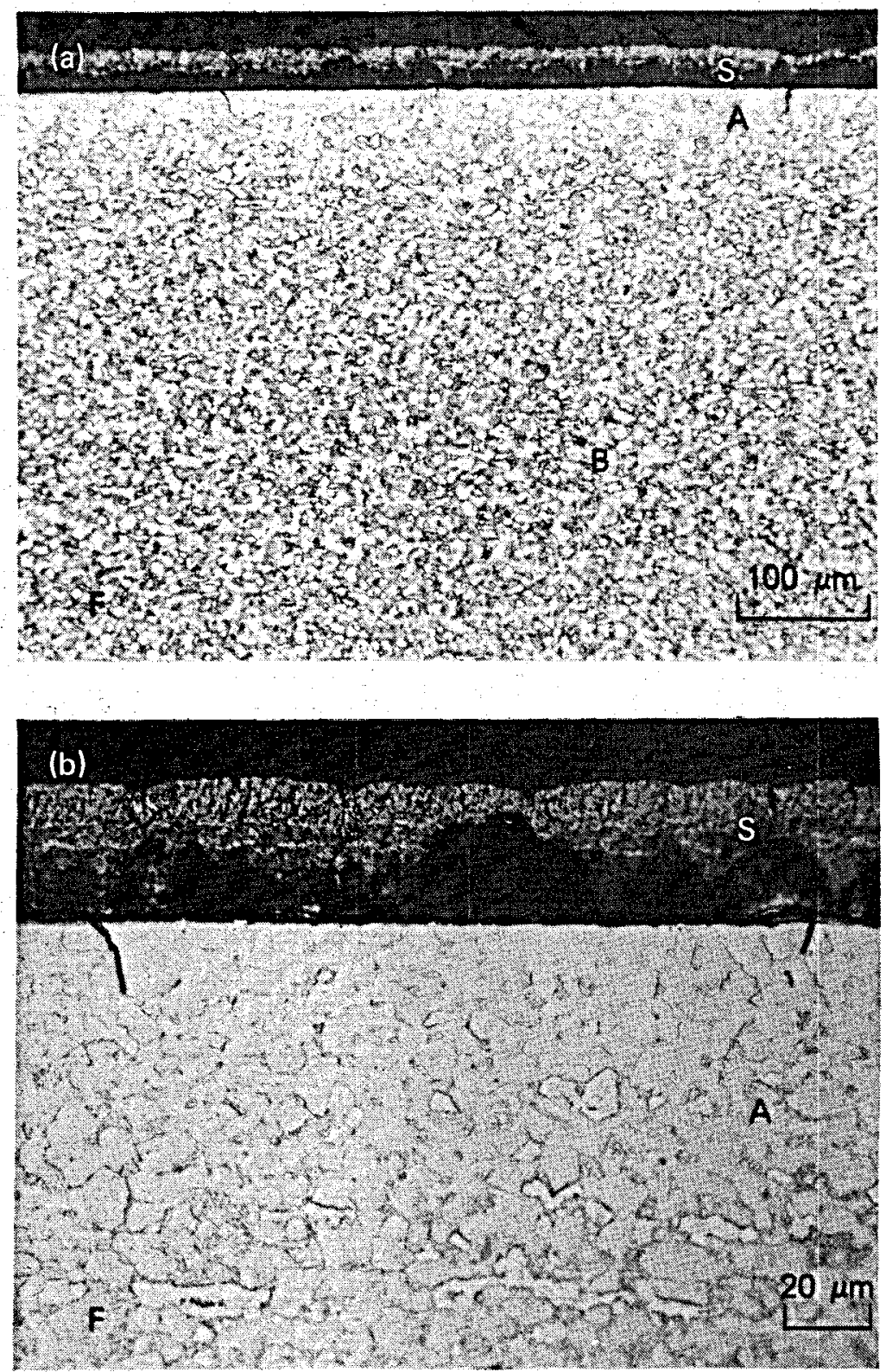

FIG. 23. Ti-6Al-4V-ELI SCC specimen exposed for $20.1 \mathrm{~h}$ to $5 \%$ quality inlet brine, unacidified brine pH 5.6; $\mathrm{S}$ indicates scale deposit, $A$ indicates $\alpha$-phase skin. The original microstructure of $\alpha$ and transformed $\beta$ is shown at B. Cracks appear to be predominantly intergranular. 


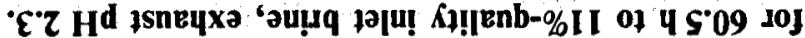

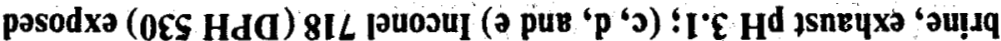
pə|u! Ki!|lenb-\%0 01 4 LE JOJ pasodxa (bIS Hda) NSEdW (q pur

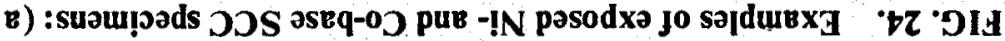
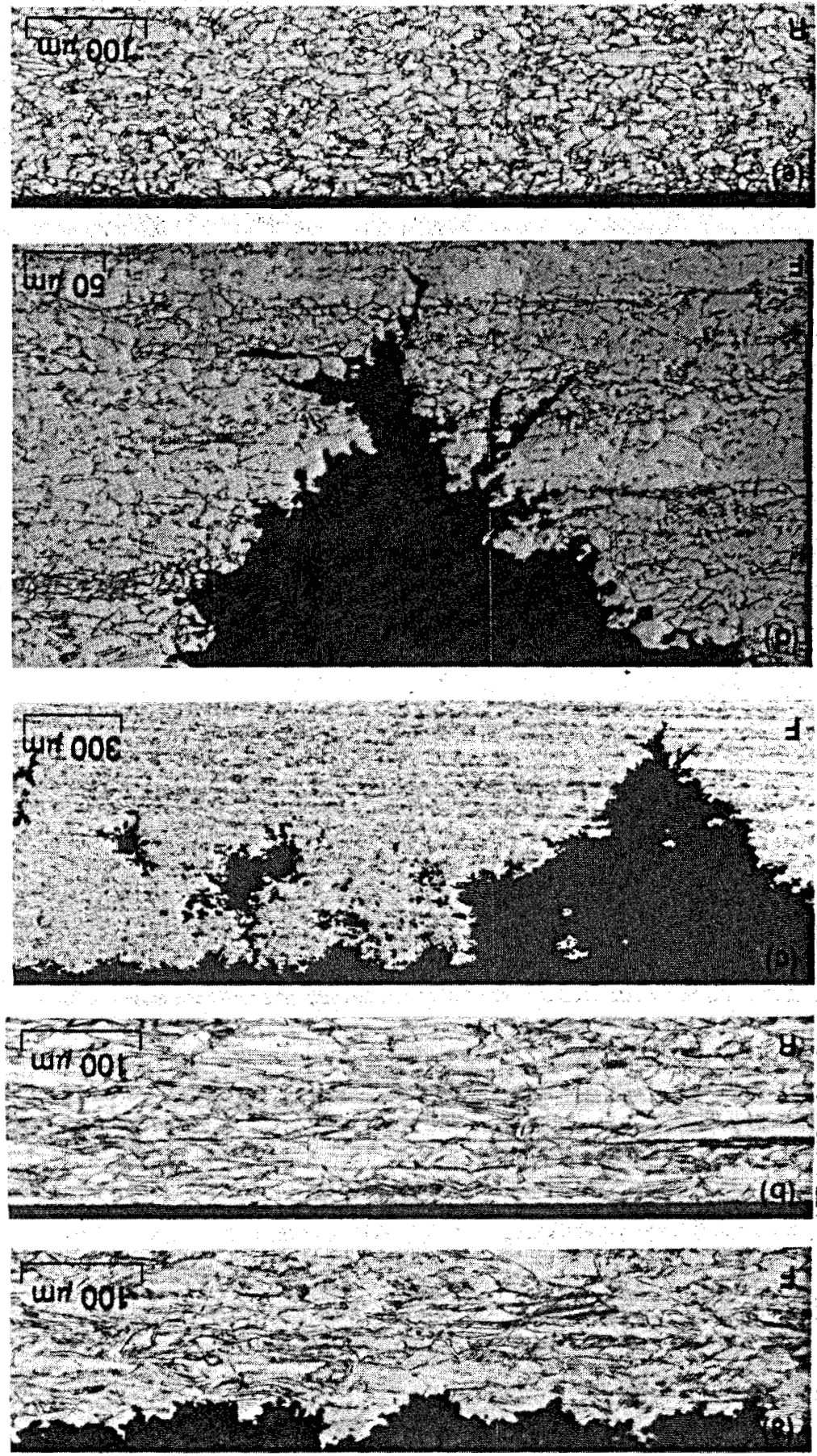

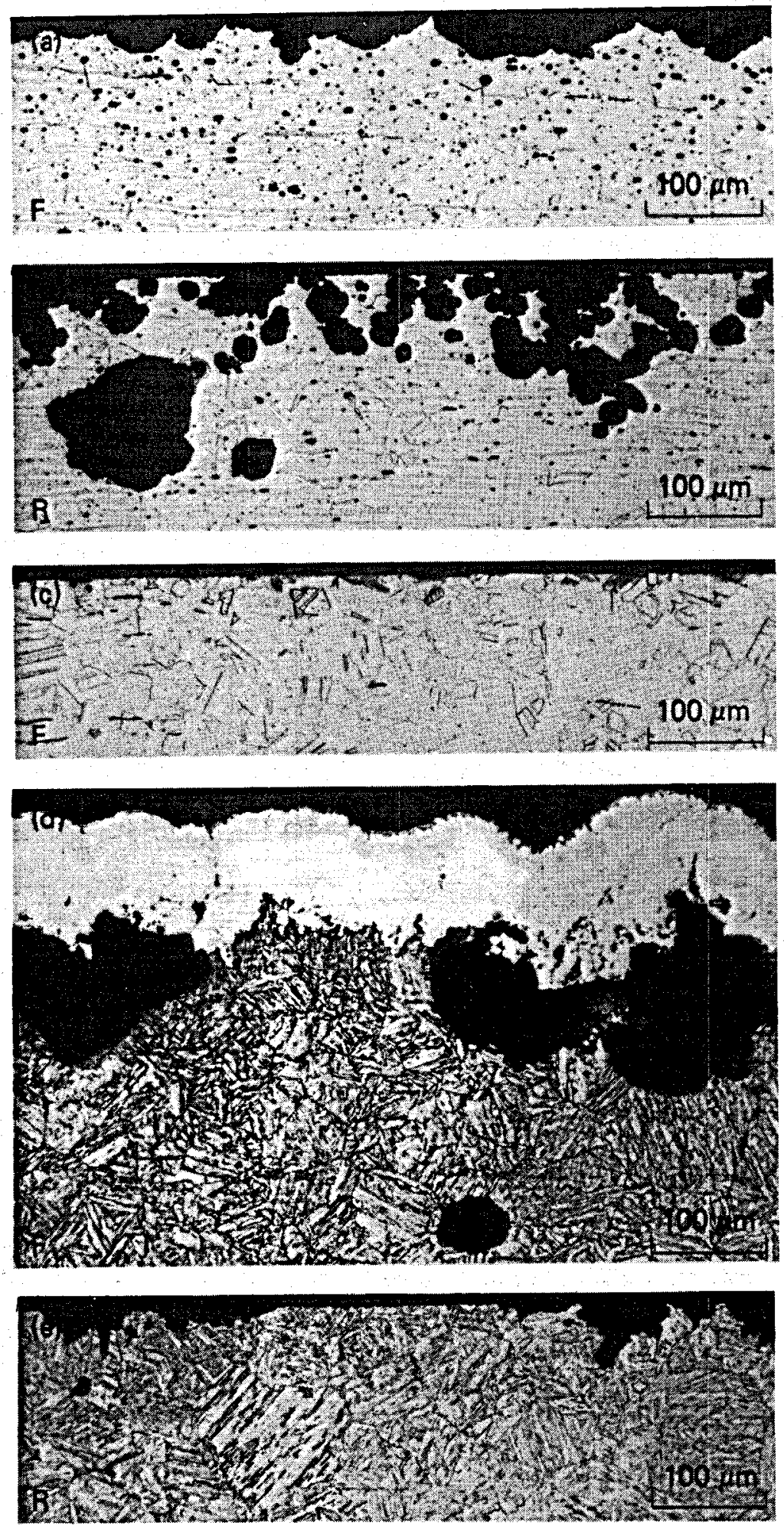

FIG. 25. Examples of exposed stainless steel (SS) SCC specimens: (a and b) 316 SS (DPH 185) and (c) 304 SS (DPH 192) exposed for $37 \mathrm{~h}$ to 0\%-quality inlet brine, exhaust pH 3.1; (d and e) $410 \mathrm{SS}$ (DPH 243) exposed for $37 \mathrm{~h}$ to $0 \%$-quality inlet brine, exhaust pH 2.6. 

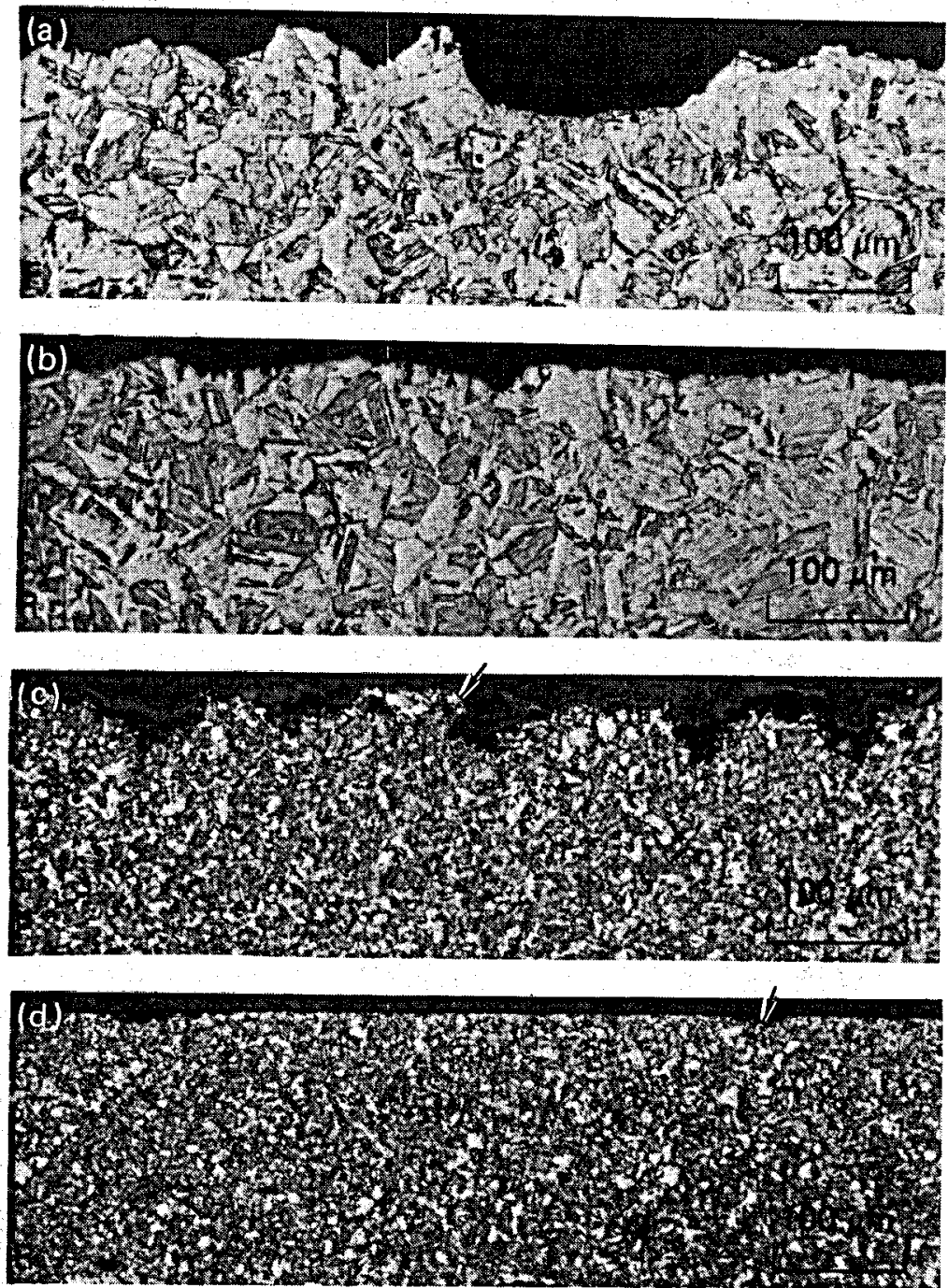

FIG. 26. Examples of exposed quenched-and-tempered mediumalloy steel SCC specimens: (a and b) 2.2.Cr-1Mo (DPH 260) exposed for $37 \mathrm{~h}$ to $0 \%$-quality inlet brine, exhaust pH 2.6; (c and d) 4130-Mo-modified (DPH 262) exposed for $7.5 \mathrm{~h}$ to $0 \%$-quality inlet brine, exhaust pH 2.7. Arrows in (c) and (d) indicate corrosion products. 
TABLE 8. Evidence of SCC in bent-beam specimens. ${ }^{2}$

\begin{tabular}{|c|c|c|c|c|}
\hline \multirow{2}{*}{$\begin{array}{c}\text { Number of } \\
\text { specimens } \\
\text { tested }\end{array}$} & \multirow[b]{2}{*}{ Alloy } & \multirow{2}{*}{$\begin{array}{c}\text { Hardness, } \\
\text { DPH }\end{array}$} & \multicolumn{2}{|c|}{$\begin{array}{l}\text { Number of specimens } \\
\text { showing cracks }\end{array}$} \\
\hline & & & in notch & on surface \\
\hline 11 & Ti6Al4V-ELI & $324-342$ & $\mathbf{0}$ & 2 \\
\hline 13 & Ti-6Al-4V & $336-354$ & 9 & $\mathbf{1}$ \\
\hline 4 & Ti-4Al-3Mo-1V & 284 & 2 & $\mathbf{0}$ \\
\hline 4 & Ti-8Al-1Mo-1V & 345 & 2 & 4 \\
\hline 2 & Ti-6Al-2Nb-1Ta-1Mo & 361 & $\mathbf{0}$ & $\mathbf{0}$ \\
\hline 2 & Ti-6Ad-6V-2Sn & 463 & $\mathbf{0}$ & $\mathbf{0}$ \\
\hline 2 & Ti-3Al-8V-6Cr-4Mo-4Zr & 418 & 1 & $\mathbf{0}$ \\
\hline 2 & Ti-3Al-8Mo-8V-2Fe & 416 & $\mathbf{0}$ & $\mathbf{0}$ \\
\hline 2 & Ti-3Al-10V-2Fe & 355 & $\mathbf{0}$ & $\mathbf{0}$ \\
\hline 2 & Ti-3Al-15V-3Cr-3Sn & 363 & 2 & $\mathbf{0}$ \\
\hline 2 & Ti-11.5Mo-6Zr-4.5Sn & 350 & 1 & $\mathbf{0}$ \\
\hline 4 & Hastelloy C-276 & 407 & 3 & $\mathbf{0}$ \\
\hline 2 & Hastelloy C-276 & 224 & - & $\mathbf{0}$ \\
\hline 2 & Inconel 718 & 520 & - & 1 \\
\hline 2 & Inconel 718 & 520 & 2 & $\mathbf{0}$ \\
\hline 4 & MP35N & 514 & $\mathbf{0}$ & 1 \\
\hline 2 & Haynes 25 & 285 & - & $\mathbf{0}$ \\
\hline 2 & AL-6X $\mathbf{X}$ & 190 & $\mathbf{0}$ & $\mathbf{0}$ \\
\hline 2 & $\mathrm{Fe}-29 \mathrm{Cr}-4 \mathrm{Mo}-2 \mathrm{Ni}$ & 251 & - & $\mathbf{0}$ \\
\hline 4 & Fe-29Cr-4Mo & 238 & 2 & $\mathbf{0}$ \\
\hline 2 & Fe-26Cr-1Mo-0.3Ti & 188 & $\mathbf{0}$ & $\mathbf{0}$ \\
\hline 2 & Fe-18Cr-2Mo & 203 & $\mathbf{0}$ & $\mathbf{0}$ \\
\hline 2 & A286 SS & 429 & - & $\mathbf{0}$ \\
\hline 2 & 316 \$S & 185 & $\mathbf{O ( P )}$ & 1(P) \\
\hline 2 & 304 SS & 192 & 0. & $\mathbf{0}$ \\
\hline 1 & 410 SS & 243 & - & (P) \\
\hline 1 & 410 SS & 243 & (P) & 1 \\
\hline 1 & 2.2Cr-1Mo steel & 260 & - & 1 \\
\hline 1 & 2.2Cr-1Mo steel & 260 & (P) & (P) \\
\hline 3 & 4130 steel & 251 & - & (P) \\
\hline
\end{tabular}

aspecimens are not listed in any ranking order.

bash indicates absence of notch; $P$ indicates excessive pitting that would obscure possible crack growth in one or more specimens in the group.

alloy. Of the combined total of $24 \mathrm{Ti}-6 \mathrm{Al}-4 \mathrm{~V}-\mathrm{ELI}$ and Ti-6Al-4V specimens, only three contained cracks outside of the notch and of these, surprisingly, one specimen of each alloy had been exposed to the unacidified brine-the least severe of the test environments. Figure 23 shows the appearance of cracks in the Ti-6Al-4V. ELI specimen exposed to unacidified brine; the scale deposit should be noted. The cracks had propagated in an alpha-phase surface layer. The presence of an alpha-phase layer (caused by oxygen contamination) was uncommon in our tests, and it was absent in the other two surface-cracked specimens. It should be pointed out that, whereas the Ti-8Al-1Mo-1V sample showed many surface cracks, these three specimens contained only a few small localized cracks $(<15 \mu \mathrm{m})$.

The alloy Ti-4Al-3Mo-1V was expected to be one of the most resistant to SCC in chlorides. ${ }^{5}$ Two sets of this alloy were exposed, and cracks were observed in the notch of the two rear specimens. Of the remaining Ti-base alloys, one set of each was exposed to comparable conditions in the second test series. The Ti-6Al-6V-2Sn specimens were heat treated to a relatively high strength level (DPH 463). They showed no 
evidence of SCC or erosion; the latter finding is consistent with the wearblade results for this alloy. The alloy Ti-6Al-2Nb-1Ta-1Mo (a high- $\alpha$ alloy) exhibited no SCC and showed good resistance to erosion. (This alloy is being evaluated for submarine hulls.) The remaining five Ti-base alloys tested are $\beta$-stabilized alloys. Specimens representing a wide range of heat-treated strength levels were prepared from each of these alloys, but insufficient time was available to test all of these specimens. The alloys were only tested in their low- to intermediate-strength levels. These alloys proved comparable to the Ti-6Al-4V and Ti-6Al-4V-ELI alloys in their resistance to SCC and erosion when exposed for equivalent times. For the $\beta$ alloys, we observed no correlation between degradation and hardness. The compressive surfaces of all Ti-base alloys were not attacked.

Four Ni- and Co-base alloys were tested. Two specimens from this group exhibited considerable degradation with cavities over $50 \mu \mathrm{m}$ deep. Figure $24 \mathrm{a}$ shows the extensive erosion suffered in a front specimen of MP35N exposed for $37 \mathrm{~h}$ to acidified $0 \%$-quality inlet brine. Evidence of SCC is also apparent, although the crack tips were blunted by the excessive erosion. The rear specimen (Fig. 24b) showed no degradation. The same alloy exposed for $20 \mathrm{~h}$ to acidified $5 \%$-quality inlet brine showed no evidence of SCC and only minor erosion with cavities ranging 4-10 $\mu \mathrm{m}$ deep. Figures $24 \mathrm{c}$ and $24 \mathrm{~d}$ show an extreme example of pitting and SCC in an Inconel 718 front specimen; cracking was predominantly intergranular. The corresponding rear specimen was not attacked (Fig. 24e). The specimens were exposed for $60.5 \mathrm{~h}$ to acidified $11 \%$-quality inlet brine. In a pair of Inconel 718 specimens exposed $18.5 \mathrm{~h}$ to acidified $5 \%$-quality inlet brine, cracks developed only in the notched region; the front specimen was only moderately eroded with a maximum cavity depth in the range of $11-20 \mu \mathrm{m}$. The MP35N and Inconel 718 specimens were in the cold-worked-andaged conditions.

Three pairs of Hastelloy C-276 specimen were exposed, two pairs in the cold-worked-and-aged condition (DPH 407) and the third pair in the annealed condition (DPH 224). One pair in the hardened condition was exposed for $60.5 \mathrm{~h}$ to acidified $11 \%$-quality inlet brine and the other pair for $20.1 \mathrm{~h}$ to acidified $5 \%$-quality inlet brine. Both pairs showed evidence of SCC but only in the notched area; both front specimens showed mild erosion attack with maximum depths of $4-10 \mu \mathrm{m}$. Despite the large difference in exposure conditions, the extent of degradation of the two pairs was similar. The unhardened pair, exposed concurrently with one of the hardened pairs during the 20.1 -h run, showed no surface degradation or SCC.

We tested one pair of Haynes 25 specimens. These were not notched and were in the annealed condition. They were exposed for $20.1 \mathrm{~h}$ to acidified $5 \%$-quality inlet brine. Only mild surface degradation was observed with maximum depths of 4-10 $\mu \mathrm{m}$.

Several ferritic stainless steels, the alloy content ranging from $18 \mathrm{Cr}-2 \mathrm{Mo}$ to $29 \mathrm{CR}-4 \mathrm{Mo}-2 \mathrm{Ni}$, were exposed either 37 or $60 \mathrm{~h}$ in the first test series. Of ten specimens, two developed cracks in the notched region. Erosion in all samples was mild with maximum depths of less than $10 \mu \mathrm{m}$; with the exception of one specimen, none of the compressive surfaces showed any damage. Two high-Ni, austenitic steels [A286, cold rolled and aged (DPH 429), and AL-6X, not heat-treatable (DPH 190)] were exposed $20 \mathrm{~h}$ to acidified 5\%-quality inlet brine. Neither showed evidence of SCC; surprisingly, the harder alloy suffered deeper erosion cavities than did the softer alloy, $(11-20 \mu \mathrm{m}$ vs $<4 \mu \mathrm{m}$, respectively).

Severe surface erosion/corrosion was observed in a pair of 316 stainless-steel specimens, as shown in Figs. $25 \mathrm{a}$ and $25 \mathrm{~b}$. Both front and rear specimens exhibited cavities more than $50 \mu \mathrm{m}$ deep. Cavities in the front specimen were typical of erosion cavities seen in other alloys, and blunted crack tips were frequently present. In contrast, the degradation of the rear specimen occurred by intrusions of pits typical of corrosion attack. Traces of the original surface could still be seen, which was unexpected in view of the relatively intense corrosion. The compressive side of each specimen showed no attack, and no evidence of sensitization was detected. A pair of 304 stainless-steel specimens was exposed to conditions similar to those for the 316 stainless-steel specimens: $37 \mathrm{~h}$, acidified $0 \%$-quality inlet brine (exhaust pH 3.1). These showed only mild surface erosion (4-10 $\mu \mathrm{m}$ maximum depth) and no evidence of SCC; the front specimen is shown in Fig. 25c. The superior resistance to degradation of 304 stainless steel over 316 stainless steel was surprising.

Figure 25d shows severe erosion/corrosion in a front-tested 410 martensitic stainless steel. The specimen was exposed for $37 \mathrm{~h}$ to acidified $0 \%$-quality inlet brine. Several layers of scale deposit formed, indicating the presence of several high-pH excursions. No scale had deposited on the rear specimen, which was 
pitted much less but still to a depth greater than $50 \mu \mathrm{m}$. Evidence of blunted crack tips could be seen. Both specimens contained corrosion pits on their compressive surfaces.

Figure 26 shows micrographs from specimen pairs of $2.2 \mathrm{Cr}-1 \mathrm{Mo}$ steel and 4130 -Mo-modified steel; both pairs were quenched and tempered. The front specimens showed extensive attack with maximum pit depths greater than $50 \mu \mathrm{m}$. A series of cracks were visible in the rear-mounted $2.2 \mathrm{Cr}-1 \mathrm{Mo}$ steel specimen (Fig. 26b). Similar cracks with blunted tips appeared to be present in the more severely eroded/corroded front specimen (Fig. 26a). The 4130-Mo-modified specimens represent one of the few examples in which corrosion product can be seen. Figure $26 \mathrm{~d}$ shows a very thin adherent corrosion film that thickens occasionally into a corrosion pit. The 4130 steel was exposed for only $7.5 \mathrm{~h}$, compared to $37.0 \mathrm{~h}$ for the $2.2 \mathrm{Cr}-1 \mathrm{Mo}$ steel; both alloys were exposed to acidified 0\%-quality inlet brine. All four specimens contained corrosion pits on the compressive side.

Although we recognized that we could not correlate our observation with any normalized environmental parameter, we still attempted some ranking of the alloys. Table 9 shows the wearblades and SCC specimens ranked according to their resistance to surface degradation. As a group, the Ti-base alloys ranked

TABLE 9. Ranking based on surface recession and cavities. ${ }^{a}$

\begin{tabular}{|c|c|c|c|c|c|}
\hline \multicolumn{3}{|c|}{ Wearblades } & \multicolumn{3}{|c|}{ SCC specimens ${ }^{b}$} \\
\hline $\begin{array}{l}\text { Number of } \\
\text { specimens }\end{array}$ & Alloy & $\begin{array}{c}\text { Hardness, } \\
\mathbf{R}_{\mathbf{C}} \\
\end{array}$ & $\begin{array}{l}\text { Number of } \\
\text { specimens }\end{array}$ & Alloy & $\begin{array}{c}\text { Hardness, } \\
\text { DPH } \\
\end{array}$ \\
\hline 1 & Ti-6Al-6V-2Sn & 43 & 1 & Ti-6Al-6V-2Sn & 463 \\
\hline 3 & Ti-6Al-4V & $34-37$ & 1 & Ti-3Al-8Mo-8V-2Fe & 416 \\
\hline \multirow[t]{2}{*}{2} & Ti-6Al-4V carbonitrided & 37 & 1 & Ti-3Al-15V-3Cr-3Sn & 363 \\
\hline & in $\mathrm{N}_{2} / \mathrm{H}_{2} / \mathrm{CH}_{4}$ & $(750)^{c}$ & 1 & Ti-3Al-10V-2Fe & 355 \\
\hline 7 & Ti-6Al-4V-ELI & $30-34$ & 8 & Ti-6Al-4V & $324-342$ \\
\hline \multirow[t]{2}{*}{1} & Haynes 25: Co-20Cr- & 51 & 1 & Ti-6Al-2Nb-1Ta-1Mo & 361 \\
\hline & 14.5W-9.5Ni-2.5Fe & & 3 & Hastelloy C-276 & $224-407$ \\
\hline 1 & $\begin{array}{r}\text { Stellite 6B: Co-30Cr- } \\
4.5 W-2.5 \mathrm{Ni}-1 \mathrm{Mo}-1 \mathrm{C}\end{array}$ & 37 & 1 & $\begin{array}{l}\text { AL-6X: } \quad \mathrm{Fe}-20 \mathrm{Cr}-24 \mathrm{Ni}- \\
6.5 \mathrm{Mo}\end{array}$ & 190 \\
\hline 1 & Haynes 25 & 20 & 1 & $\mathrm{Fe}-29 \mathrm{Cr}-4 \mathrm{Mo}-2 \mathrm{Ni}$ & 251 \\
\hline $\mathbf{I}$ & Ti-6Al-2Nb-1Ta-1Mo & 32 & 7 & Ti-6Al-4V-ELI & 336-354 \\
\hline \multirow[t]{2}{*}{2} & MP35N: $35 \mathrm{Co}-35 \mathrm{Ni}-$ & $46-47$ & 1 & Ti-3Al-8V-6Cr-4Mo-4Zr & 418 \\
\hline & $20 \mathrm{Cr}-9.5 \mathrm{Mo}$ & & 1 & Ti-11.5Mo-6Zr-4.5Sn & 350 \\
\hline \multirow[t]{2}{*}{3} & Hastelloy C-276: Ni- & $10-47$ & 2 & $\mathrm{Fe}-29 \mathrm{Cr}-4 \mathrm{Mo}$ & 238 \\
\hline & $16 \mathrm{Cr}-15.5 \mathrm{Mo}-5.5 \mathrm{Fe}-3.3 \mathrm{~W}$ & & 2 & Ti-8Al-1Mo-1V & 345 \\
\hline 1 & $\mathrm{Ti}-0.3 \mathrm{M}-0.8 \mathrm{Ni}$ & 6 & 2 & Ti-4Al-3Mo-1V & 284 \\
\hline \multirow[t]{2}{*}{1} & Ti-6Al-4V plasma-sprayed & 45 & 1 & Fe-1 $8 \mathrm{Cr}-2 \mathrm{Mo}$ & 203 \\
\hline & with 90Ta-10W & & 1 & Haynes 25 & 285 \\
\hline \multirow[t]{2}{*}{$\mathbf{1}$} & 2.2Cr-1Mo Steel & 21 & 1 & 304 stainless steel & 192 \\
\hline & & & 2 & MP35N & 514 \\
\hline & & & 1 & A-286: $\mathrm{Fe}-26 \mathrm{Ni}-14.5 \mathrm{Cr}-$ & 429 \\
\hline & & & & 1.2Mo-2Ti-0.35Al & \\
\hline \multirow{5}{*}{. } & & & 2 & $\begin{array}{l}\text { Inconel 718: Ni-19Cr- } \\
18 \mathrm{Fe}-5(\mathrm{Nb}+\mathrm{Ta})-3 \mathrm{Mo}- \\
0.9 \mathrm{Ti}-0.5 \mathrm{Al}\end{array}$ & 520 \\
\hline & & & 1 & 316 stainless steel & 185 \\
\hline & & & 1 & 2.2Cr-1Mo steel & 260 \\
\hline & & & 2 & 4130 steel & $254-262$ \\
\hline & & & 1 & 410 stainless steel & 243 \\
\hline
\end{tabular}

Alloys listed in order of increasing degradation.

bFront SCC specimens are listed only.

CMaximum microhardness (DPH) of cross section of hardened case. 
the highest. The lack of correlation between resistance to degradation and hardness is clearly evident for both types of specimens. Considering the combined effects of erosion, corrosion, and SCC (and excluding the presence of notches and the Ti-8Al-1Mo-IV alloy), the Ti-base alloys promise the best combination of resistance to degradation in these nozzle exhaust environments.

\section{DISCUSSION}

In a recent review, Preece ${ }^{8}$ points out that, to date, no relationship has been formulated that relates the erosion resistance of a material to its properties independent of the class or condition of the material. The difficulty is that erosion is a complex phenomenon involving a number of material properties. Because of the added complexities of corrosion and nonuniform brine conditions, it is not surprising that we could not obtain a systematic correlation between erosion and hardness. Furthermore, several inverse results between erosion resistance and hardness were seen.

The generally superior erosion resistance of the Ti-base alloys compared to the Ni- and Co-base alloys must result, at least in part, from the higher rates of surface repassivation that are expected in the brines for the Ti-base alloys relative to the $\mathrm{Ni}$ - and Co-base alloys. The lower resistance of the Mo-containing wearblades (MP35N and C-276) compared to that of the Co-base wearblades (Stellite 6B and Haynes 25) may in fact have resulted from a slower rate of repassivation imparted by Mo or from a faster rate of repassivation imparted by $\mathrm{Co}$ compared to $\mathrm{Ni}$. The relative hardness of these four alloys apparently had little if any effect on the extent of damage. For the Ti-base alloys, erosion resistance of the wearblades can be roughly correlated with hardness, but a corresponding ranking for erosion resistance from the SCC specimens shows many exceptions. Most of the Ti-base SCC specimens were exposed for $20 \mathrm{~h}$ in the second test series, and the variation in erosion resistance therefore cannot be attributed to either environment or exposure time alone. We suggest that resistance of the Ti-base alloys to corrosion, especially that resistance related to repassivation of their surfaces, greatly affects their erosion resistance. In pitting experiments using Ti foils in halogen solutions, Beck ${ }^{9}$ showed that repassivation begins instantaneously and reaches completion in less than $1 \mathrm{~s}$.

Cavities or craters resulting from erosion by either solid-particle, ${ }^{10-12}$ liquid-droplet, 8,13 or cavitation-induced $8,14,15$ impacts have frequently been reported. Evidence of plastic deformation associated with the formation of these cavities has been reported, at least for ductile materials. Generally, a raised lip was formed by a Brinelling or extrusion process when the eroding agent struck the surface at high impact angles. At low impact angles, erosion resulted primarily from plowing or micromachining, although these two processes can also occur at high impact angles once the surface has become roughened. " Ripple formation, slip bands, work hardening, fatigue cracking, crack propagation, and hill-and-valley formation by local extrusions all indicate the role played by plastic deformation in erosion studies. In our work, however, we could not find any visual evidence of surface plastic deformation along the tip of the wearblades where most of the degradation occurred. We suggest that any additive effects of repeated impact that normally lead to easily observed plastic deformation were probably obliterated by concomitant corrosion.

Considerable evidence exists ${ }^{8,16}$ that the erosion rate for ductile materials is greatest at an intermediate impact angle of about $0.35 \mathrm{rad}$. In our experiments, the leading-edge tip radius provided a range of impact angles of 0.17 to 1.57 rad, but the receding and flattening of the tip surface indicated that the maximum erosion occurred at about $1.57 \mathrm{rad}$. This apparent anomaly probably resulted from a reduction of impact velocity and impact mass along the tapered surfaces due to deflection of the supersonic liquid flow a way from the wearblade tip. Such deflection would produce a pressure discontinuity resulting in a pair of lateral shock fronts (one on each side of the wearblade) that would interact with and retard the flow on either side of the tip. If the particles or liquid droplets primarily responsible for the erosion were $20 \mu \mathrm{m}$ or less in diameter, then they would be easily deflected together with the liquid/vapor flow stream. ${ }^{17}$ Although particulate and droplet size were not measured in our field studies, these dimensions are within the ranges of water-droplet sizes observed in our laboratory nozzle-expansion tests and of particulate sizes observed in our scale deposits.'

Tilly noted the contribution of secondary damage to high-impact-angle erosion by fragments from primary impacts. ${ }^{12}$ Such damage should have resulted in uniform erosion, but we observed formation of deep cavities instead; on some wearblades, we could still see evidence of machining marks around these cavities. In 
their studies with water drops, Adler and Hooker state that once an erosion pit forms, enlargement occurs very rapidly. ${ }^{13}$ Interestingly, erosion pits in the Ti-base alloys and the two Co-base alloys, Haynes 25 and Stellite 6B, were quite localized in the SCC specimens; in contrast, such erosion was continuous along the entire tensile surface in alloys such as MP35N, Hastelloy C-276, Inconel 718, and many of the stainless steels.

Why do cavities in wearblades grow as large as they do while the surrounding areas are not significantly pitted? This was especially noted in the Ti-base wearblades. The fine structure of the surfaces of wearblade cavities resembled that observed by Beck in pitting studies on $\mathrm{Ti}^{18}$ and this similarity suggests that corrosion could be an important factor in the growth of these cavities. We propose that the damage from particulates and water droplets in the acidified two-phase flow occurs at a sufficiently low rate that the surfaces of the Ti-base alloys are readily repassivated. This repassivation would also account for the relatively minor damage seen for runs shorter than about $20 \mathrm{~h}$. Once a critical-size cavity forms, however, trapped liquid becomes continuously more concentrated and more acidic, thus making repassivation more difficult. As the cavity grows, corrosion increasingly dominates erosion; as is typical of pitting corrosion, ${ }^{19}$ the process is autocatalytic, and the degradation accelerates continuously.

For alloys for which the repassivation rates are relatively slow, critical-size cavities form more readily and are more numerous. Cavity formation leads to a general surface recession, as was observed for the Hastelloy C-276 wearblade, and in the extreme, the whole wearblade tip and tapered surface erodes and corrodes away, as occurred with the $2.2 \mathrm{Cr}$ - 1 Mo steel wearblade. We attributed the more open, void-like appearance of the cavity-wall fine structure in $\mathrm{Co}$ - and $\mathrm{Ni}$-base alloys compared to Ti-base alloys to the more rapid corrosion of these non-Ti-base alloys.

Our analyses of the SCC specimens also indicated synergism between erosion and corrosion. Even in cases in which we observed significant erosion and corrosion for front specimens exposed directly to nozzle exhaust (such as Inconel 718 and MP35N), we detected no damage for the corresponding shielded rear specimens. In the case of the shielded rear 316-stainless-steel specimen, the extensive damage encountered on the tensile surface suggested that corrosion was a dominant factor, but no degradation was observed on the compressive surface of either the front or rear specimen. It appeared that, in addition to erosion of the protective oxide film, tensile stresses aid in inducing and maintaining corrosive actions, and such stresses become especially important where corrosion is prominent. Although one would normally expect SCC to be dominant in the presence of stress, corrosion (or erosion combined with corrosion) evidently progressed fast enough in many cases to blunt the crack tips as they developed; evidence of crack tip blunting was clearly seen in a number of specimens, e:g., the front 316-stainless-steel specimen. For the medium- and low-alloy steels, corrosion was apparent on both tensile and compressive surfaces but to a much greater extent on the tensile surface; this clearly indicated the roles of tensile stresses and erosion in accelerating corrosion.

Table 9 shows a large inconsistency in the ranking for erosion resistance of SCC specimens and wearblades made of the Ni- and Co-base alloys. For example, the Hastelloy C-276 specimens were ranked considerably above the Haynes 25 specimens used for SCC, but the reverse ranking was evident for the corresponding wearblades. The two Haynes 25 SCC specimens, two of the six C-276 SCC specimens, and the four Ni- and Co-base wearblades of Figs. 13 and 14 were exposed for $20 \mathrm{~h}$ in the second test series. Both pairs of SCC specimens were in the as-annealed condition (the Haynes 25 was harder than the C-276); the corresponding wearblades were in the hardened condition. Neither pair of SCC specimens showed evidence of cracks. Only the front Haynes 25 specimen was eroded, however, but with relatively shallow cavities: 4-10 $\mu \mathrm{m}$ maximum. depth. This reversal in ranking of wearblades and SCC specimens indicated that the presence of concomitant stress can greatly modify the propensity of alloys to erosion or corrosion-assisted erosion.

The rate of stress-corrosion-cracking, especially of crack initiation, depends strongly on stress level, microstructure, alloy strength, and environment. Because our tests did not permit a systematic study of these factors, our ranking of the alloys must be considered only tentative. In addition, it is difficult to explain the environmental factors that caused the extensive attack on 316 stainless steel and Inconel 718 . The nature of the scale deposits on one of the 410 stainless-steel specimens was also curious. Similar deposits were not observed on any of the other test specimens.

At best, we can make only general comments about SCC. Except for these isolated anomalies, the susceptibility of the various alloys to SCC are not significantly different. Of the more corrosion-resistant alloys tested, the Ti-base alloys showed the greatest tendency to form cracks in the presence of a notch, but 
many of these Ti-base alloys showed promise for use with notch-free surfaces. Furthermore, all but four of the Ti-base SCC specimens were loaded into the plastic range-considerably above normal working stresses. Taking both erosion and SCC into account, we suggest that the Ti-base alloys would best resist degradation from the nozzle exhaust of acidified, highly mineralized two-phase brine at $104^{\circ} \mathrm{C}$.

Scale deposits could be protective against surface attack, and this possibility should be further examined. Our limited observations indicated that tenaciously adhering scale greatly reduced surface attack, as evidenced by the Si-rich scale deposited at $104^{\circ} \mathrm{C}$. As demonstrated by the wearblade exposed to unacidified brine, however, the scale particulates first impinging the base metal do cause erosion, and these particulates may accelerate long-time erosion if an adherent scale layer is not formed. Furthermore, the possible access of fluids to regions where the scale is porous or where it may have cracked or flaked off to expose metal may provide crevice-like conditions for accelerated erosion/corrosion.

\section{SUMMARY}

We exposed Ti-, Fe-, and Co-base alloys in the form of nozzles, wear-blades, and stress-corrosioncracking (SCC) specimens to high-velocity, high-salinity, highly mineralized two-phase brines at $104^{\circ} \mathrm{C}$. Erosion of wearblades occurred by the formation and growth of cavities concentrated along the center of the wearblade tips. The tip surfaces receded in the direction of the flow and became flattened, indicating that erosion was greatest at impact angles near $1.57 \mathrm{rad}$.

Wearblades and SCC specimens made of Ti-base alloys showed the best resistance to erosion. Although erosion resistance of the Ti-base alloys generally increased with increasing hardness, we obtained no correlation between erosion resistance and hardness for other alloys or for all the alloys taken together. The erosion-resistance rankings for the $\mathrm{Ni}$ - and Co-base alloys were inconsistent when the results of the wearblades and SCC specimens were compared.

Because the fine structure of the cavity walls resembled that of electrochemically pitted surfaces, we propose that degradation occurs by corrosion-assisted erosion and that it is largely controlled by repassivation kinetics. The formation of stable critical-size cavities must be inversely related to the ability of the surface to repassivate; once cavities form, they grow by erosion (assisted by corrosion pitting) at an accelerating rate. Disparities in rankings of wearblades and SCC specimens might be attributed to the different erosion/corrosion environments of the two corresponding locations in the test assembly or to the influence of stress contributions to corrosion-assisted erosion for the SCC specimens.

For alloys with stable passive films, degradation (except where SCC might occur) was not generally induced by tensile stress. For soluble oxide films, (e.g., those formed on the low- or intermediate-alloy steels), however, tensile stress accelerated corrosion or pitting, even in the absence of erosive attack. Synergism between erosion, corrosion, and tensile loading resulted in an autocatalytic accelerated rate of degradation. Evidence of SCC was noted in each of the alloy groups.

Taking into account both erosion and SCC, we suggest that the Ti-base alloys offer the best resistance to degradation in acidified high-velocity two-phase brine at $104^{\circ} \mathrm{C}$. The presence of an adherent scale deposit may be protective against erosion/corrosion, and this possibility merits further investigation.

\section{ACKNOWLEDGMENTS}

The authors thank G. E. Tardiff for his leadership, encouragement, and support in this study and R. E. Garrison for his help with the preparation of specimens. The SEM analyses were performed by W. J. Steele. Heat treatment of test materials was done by F. A. Dishong. The carbonitrided specimens were furnished by J. M. Johnson, the 4130-steel specimens by R. F. Hehmann, Case Western Reserve University, and the Ti-6Al-4V ELI forgings by Dr. C. C. Chen of the Wyman-Gordon Company. The authors also wish to acknowledge the support of those people involved in the field studies. 


\section{REFERENCES}

1. A. L. Austin, A. W. Lundberg, L. B. Owen, and G. E. Tardiff, The LLL Geothermal Energy Program Status Report - January 1976-January 1977, Lawrence Livermore Laboratory, Livermore, Calif., UCRL50046-76 (1977).

2. A. Goldberg and R. P. Kershaw, Evaluation of Materials Exposed to High-Velocity, High-Salinity, Highly Mineralized Geothermal Brine, Lawrence Livermore Laboratory, Livermore, Calif., UCRL80755, (1978).

3. G. E. Tardiff, LLL Total Flow Geothermal Program: Summary of Two-Phase Nozzle Tests for Scale Control and Materials Performance, Lawrence Livermore Laboratory, Livermore, Calif., UCID-17636 (1977).

4. R. W. Staehle, A. J. Forty, and D. van Rooyen, Eds., Fundamental Aspects of Stress Corrosion Cracking, (Nat. Assoc. Corr. Eng., Houston, Texas, 1969).

5. M. J. Blackburn, J. A. Feeney, and T. R. Beck, "Stress Corrosion Cracking of Titanium Alloys," in Advances In Corrosion Science and Technology, M.G. Fontana and R.W. Staehle, Eds. (Plenum Press, New York, 1973), vol. 3, p. 67.

6. R. L. Cowan and C. S. Tedman, Jr., "Intergranular Corrosion of Iron-Nickel-Chromium Alloys," in Advances In Corrosion Science and Technology, M. G. Fontana and R. W. Staehle, Eds. (Plenum Press, New York, 1973), vol. 3, p. 293.

7. T. R. Beck,"Stress Corrosion Cracking of Titanium Alloys," J. Electrochem. Soc. 114, 551 (1967).

8. C. M. Preece, "Erosion," Ann. Rev. Mater. Sci. 7, 95 (1977).

9. T. R. Beck, "Pitting of Titanium," J. Electrochem. Soc. 120, 1310 (1973).

10. I. M. Hutchings and R. E. Winter, "Particle Erosion of Ductile Metals: A Mechanism of Material Removal," Wear 27, 121 (1974).

11. J. W. Edington and I. G. Wright, "Study of Particle Erosion Damage in Haynes Stellite 6B: Scanning Electron Microscopy of Eroded Surfaces," Wear 48, 131 (1978).

12. G. P. Tilly, "A Two-Stage Mechanism of Ductile Erosion," Wear 23, 87 (1973).

13. W. F. Adler and S. V. Hooker, "Water Drop Impact in Zinc Sulfide," Wear 48, 103 (1978).

14. B. Vyas and C. M. Preece, "Cavitation-Induced Deformation of Aluminum," in Erosion, Wear, and Interfaces with Corrosion, Special Technical Publication 567 (ASTM, Philadelphia, Penn., 1974), p. 77.

15. F. Erdmann-Jesnitzer and H. Louis, "Studies on Cavitation Damage," in Erosion, Wear, and Interfaces with Corrosion, Special Technical Publication 567 (ASTM, Philadelphia, Penn., 1974), p. 171.

16. I. Finnie, "Some Observations on the Erosion of Ductile Metals," Wear 19, 81 (1972).

17. G. P. Tilly and W. Sage, "The Interaction of Particle and Material Behavior in Erosion Processes," Wear 16, 447 (1970).

18. T. R. Beck, "Pitting of Titanium," J. Electrochem. Soc. 12, 1317 (1973).

19. A. Goldberg and L. B. Owen, "Pitting Corrosion and Scaling of Carbon Steels in Geothermal Brine," Corrosion 35, 114 (1979). 